\title{
Zystische Fibrose (Mukoviszidose) im Kindes- und Jugendalter
}

\author{
Sabina Schmitt-Grohé, Michael J. Lentze und Jobst Henker
}

In Deutschland ist die Mukoviszidose mit einer Inzidenz von 1:3300-1:4800 die häufigste autosomal-rezessiv vererbte Multisystemerkrankung.

\section{Genetische Grundlagen und Pathophysiologie}

Sabina Schmitt-Grohé und Michael J. Lentze

Der genetische Defekt bei zystischer Fibrose (CF, Mukoviszidose) liegt auf dem langen Arm von Chromosom 7. Das CF-Gen umfasst 250.000 Basenpaare, die das 1480 Aminosäuren enthaltende Protein, das Cystic-fibrosis-transmembrane-regulator(CFTR)-Protein kodieren. Inzwischen sind mehr als 2000 Mutationen bekannt. Die CFTR-Mutationen werden in 6 Klassen eingeteilt (Abb. 1):

- Klasse I: CFTR wird überhaupt nicht synthetisiert.

- Klasse II: Aufgrund fehlerhafter Faltung im endoplasmatischen Retikulum findet kein Processing von funktionstüchtigem CFTR-Protein statt.

- Klasse III: gestörte Aktivierung und Regulation des CFTR-Proteins.

- Klasse IV: Bei dieser Mutation findet sich ein gestörter Ionenfluss.

S. Schmitt-Grohé $(\bowtie) \cdot M$. J. Lentze

Universitätsklinikum Bonn, Zentrum für Kinderheilkunde, Bonn, Deutschland

E-Mail: sabina.schmitt-grohe@ukb.uni-bonn.de; michael. lentze@ukbonn.de

J. Henker

Klinik und Poliklinik für Kinder- und Jugendmedizin,

Universitätsklinikum Carl Gustav Carus Dresden, Dresden, Deutschland

E-Mail: jobst.henker@uniklinikum-dresden.de
- Klasse V: Bei dieser Mutation liegt eine reduzierte Menge an intaktem Protein liegt vor.

- Klasse VI: Ein akzelerierter Abbau des CFTR findet statt.

Die häufigste Mutation in Deutschland ist die Klasse-IIMutation delta F508 mit einer Prävalenz von $67 \%$ (delta F508 homozygot $47 \%$ ), ähnliche Zahlen gelten für Mitteleuropa (Prävalenz $62 \%$ ). Die europäisch-stämmigen Einwohner der USA sind zu $50 \%$ delta F508 homozygot, nur $10 \%$ sind nicht heterozygot für diese Mutation.

Pathophysiologisch führt der Gendefekt zum Mangel an funktionstüchtigem CFTR Protein. CFTR ist ein cAMP-abhängiger Chloridkanal mit Expression an apikalen Membranen von exkretorischen Drüsen. Folgen des Mangels an funktionstüchtigem CFTR Protein sind eine Hyposekretion von Chlorid und Bikarbonat in das Lumen, z. B. der Bronchien. Konsekutiv ist der $\mathrm{pH}-$ Wert der Atemwegsflüssigkeit (airway surface liquid, ASL) vermindert. Diese Azidifierung führt zu signifikanten Funktionsdefiziten in der bakteriellen Abwehr, insbesondere der angeborenen Immunität.

In der Folge kommt es zu einer Aktivierung des epithelialen Natriumkanals (ENAC) und alternativer Chloridkanäle. Mit der Hyperabsorption von Natrium in die Zelle geht eine Volumendepletion des Flüssigkeitsfilmes auf dem Epithel (z. B. ASL) einher. Auf dem Atemwegsepithel führt dies zu einem Verlust der Zilienmotilität und einer verminderten mukoziliären Clearance. Der Schleim löst sich nicht von den apikalen Oberflächen der Bronchien.

In den Schweißdrüsenzellen wird das sezernierte Chlorid im Ausführungsgang der Schweißdrüse nicht mehr zurücktransportiert mit der Folge eines hohen Chloridgehaltes im Schweiß, welches durch den Schweißtest mittels PilokarpinIontophorese gemessen werden kann.

Zusammenfassend führt die Fehlfunktion des CFTRChloridkanals an der Oberfläche der sekretorischen Epithel- 


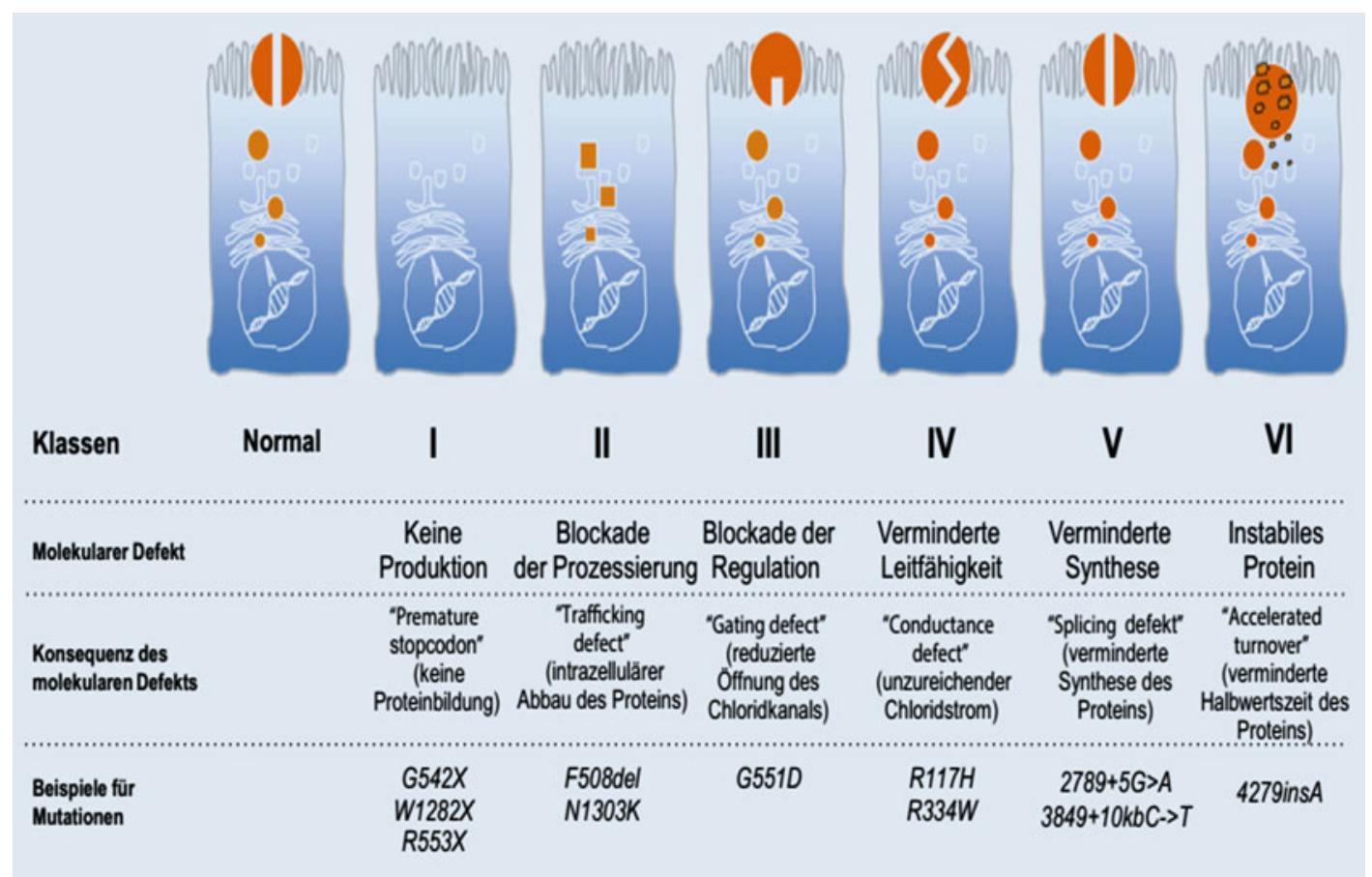

Abb. 1 Klassen der CFTR-Mutationen (mit freundl. Genehmigung von van Konigsbruggen-Rietschel et al. 2017)

zellen von exokrinen Drüsen mit Ausnahme der Schweißdrüsen zur Obstruktion durch visköses Sekret und zu verschiedenen klinischen Manifestationen (Abb. 2).

In Bezug auf die Schwere des Krankheitsverlaufes finden sich große Unterschiede. Bei Delta-F508-Homozygoten findet sich eine Assoziation zur Pankreasinsuffizienz, aber wenig Korrelationen zwischen dem CFTR-Genotyp und dem pulmonalen Phänotyp. Informationen zum Genotyp-Phänotyp-Verhältnis bietet die Internetplatform CFTR2 (https://cftr2.org/). Als krankheitsverursachend gelten 346 Mutationen.

Wichtiger als der CFTR-Genotyp für den pulmonalen Verlauf sind Modifiergene für TGFß, Mannose binding lectin, Interleukin-8 (IL-8) und Umweltfaktoren. In Studien mit eineiigen Zwillingen konnte nur maximal ein Einfluss von $25 \%$ der CFTR Mutation auf die Lungenerkrankung gefunden werden. Die obstruktive Lungenerkrankung ist derzeit die primäre Ursache der Morbidität und zu $80 \%$ für die Mortalität bei Mukoviszidose verantwortlich.

Der Anteil der erwachsenen Patienten nimmt zu: Von 5720 Patienten in Deutschland sind 3250 (57\%) $\geq 18$ Jahre alt. Die mittlere Überlebenszeit der Mukoviszidose liegt in Deutschland bei 40 Jahren.

\section{Diagnostik}

Sabina Schmitt-Grohé und Michael J. Lentze
Für die Diagnose Mukoviszidose muss entsprechend der Leitlinie mindestens ein diagnostischer Hinweis vorliegen und eine CFTR-Funktionsstörung nachgewiesen sein.

Diagnostische Hinweise sind

1. ein positives Neugeborenenscreening oder

2. Geschwister mit Diagnose einer Mukoviszidose oder

3. mindestens 1 klinischer Hinweis auf eine Mukoviszidose.

Der Nachweis einer CFTR-Funktionsstörung erfolgt durch

1. erhöhte Schweißchloridwerte $(\geq 60 \mathrm{mmol} / \mathrm{l})$ bei mindestens 2 unabhängigen Messungen oder

2. Nachweis zweier Mukoviszidose-verursachenden CFTRMutationen (in trans) oder

3. Nachweis einer charakteristischen Abnormalität der CFTR-Funktion mittels nasaler Potenzialdifferenzmessung (NPD) oder intestinaler Kurzschlussstrommessung (ICM).

\subsection{Neugeborenenscreening}

Ein flächendeckendes Neugeborenenscreening in Deutschland wurde 2016 eingeführt: Fersenblut wird auf immunreaktives Trypsin (IRT, Abb. 3) untersucht. Bei CF finden sich erhöhte Werte durch Pankreasschädigung. Werte zwischen der 99,0.und 99,9.-Perzentile werden auf pankreatitisassoziertes Protein (PAP) untersucht. Liegt der Wert unter der 87,5.Perzentile, entspricht dies einem negativen Testergebnis. Wird 


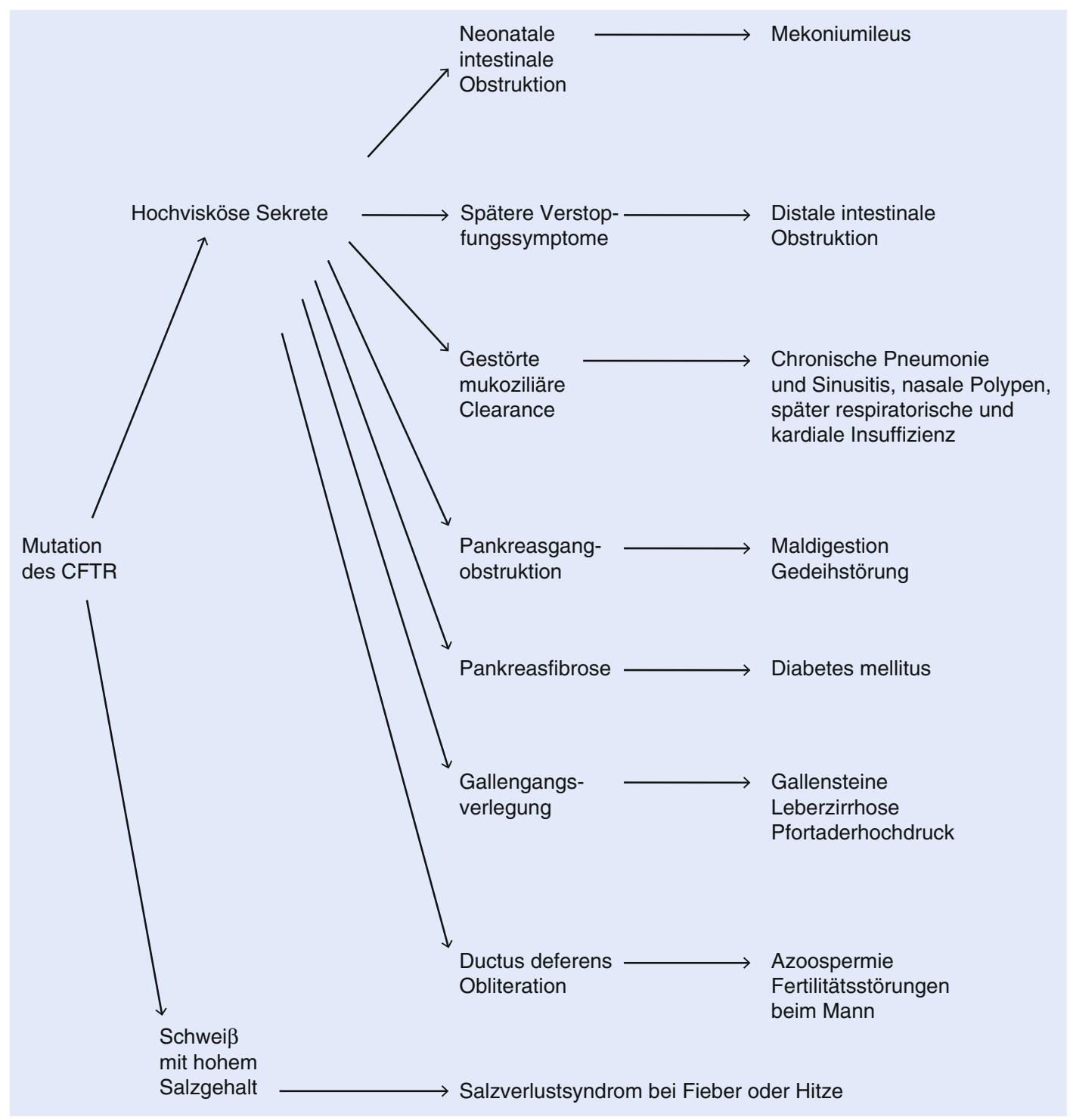

Abb. 2 Pathophysiologie der Mukoviszidose

der Cut-off ( $\geq 99$,8.-Perzentile) überschritten, erfolgt eine Untersuchung auf die in Deutschland 31 häufigsten CFTRMutationen. Aufgrund der vorgesehenen Gendiagnostik kann die Aufklärung nur durch einen Arzt erfolgen. Im Falle einer Hebammengeburt ist das Screening auf Mukoviszidose innerhalb von 28 Tagen durch einen Arzt nachzuholen.

\section{Pulmonale Manifestationen}

Sabina Schmitt-Grohé und Michael J. Lentze

Die Lungenerkrankung bei Mukoviszidose ist durch eine chronische Atemwegsinfektion mit Progression zu Bronchiektasen, Belüftungsstörungen bis zur respiratorischen Insuffizienz mit Hypoxie und Hyperkapnie charakterisiert.

\section{Inflammation und Infektion}

Bei Geburt finden sich bereits strukturelle Veränderungen in der Lunge, aber wenig Inflammation. Allerdings ist bei humanen CF-Feten schon eine erhöhte Expression von proinflammatorischen Molekülen nachweisbar. Doch sehr schnell kommt es zur Infektion mit massiver inflammatorischer Antwort auf den pathogenen Erreger. NeutrophilenElastase (freie und ungebundene) wird sehr früh bei Säuglingen mit $\mathrm{CF}$ in den Atemwegen nachgewiesen. Diese und andere neutrophile Proteasen (z. B. Cathepsin S) sowie Matrix-Metalloproteinasen gelten als Hauptursache für die Zerstörung von Lungengewebe und die Entstehung von Bronchiektasen. Keine andere Lungenerkrankung induziert eine derart frühe, anhaltende und intensive inflammatorische Reaktion, wie bei CF. Diese anhaltende, perpetuierende Entzündungsreaktion verläuft ohne Verbesserung. Als Trigger für 
Abb. 3 Neugeborenenscreening: Der Cut-off des pankreatitisassoziierten Proteins (PAP) ist vom verwendeten Testkit abhängig und entspricht der 87,5.Perzentile der Normalpopulation (mit freundl. Genehmigung von Nahrig et al. 2017)

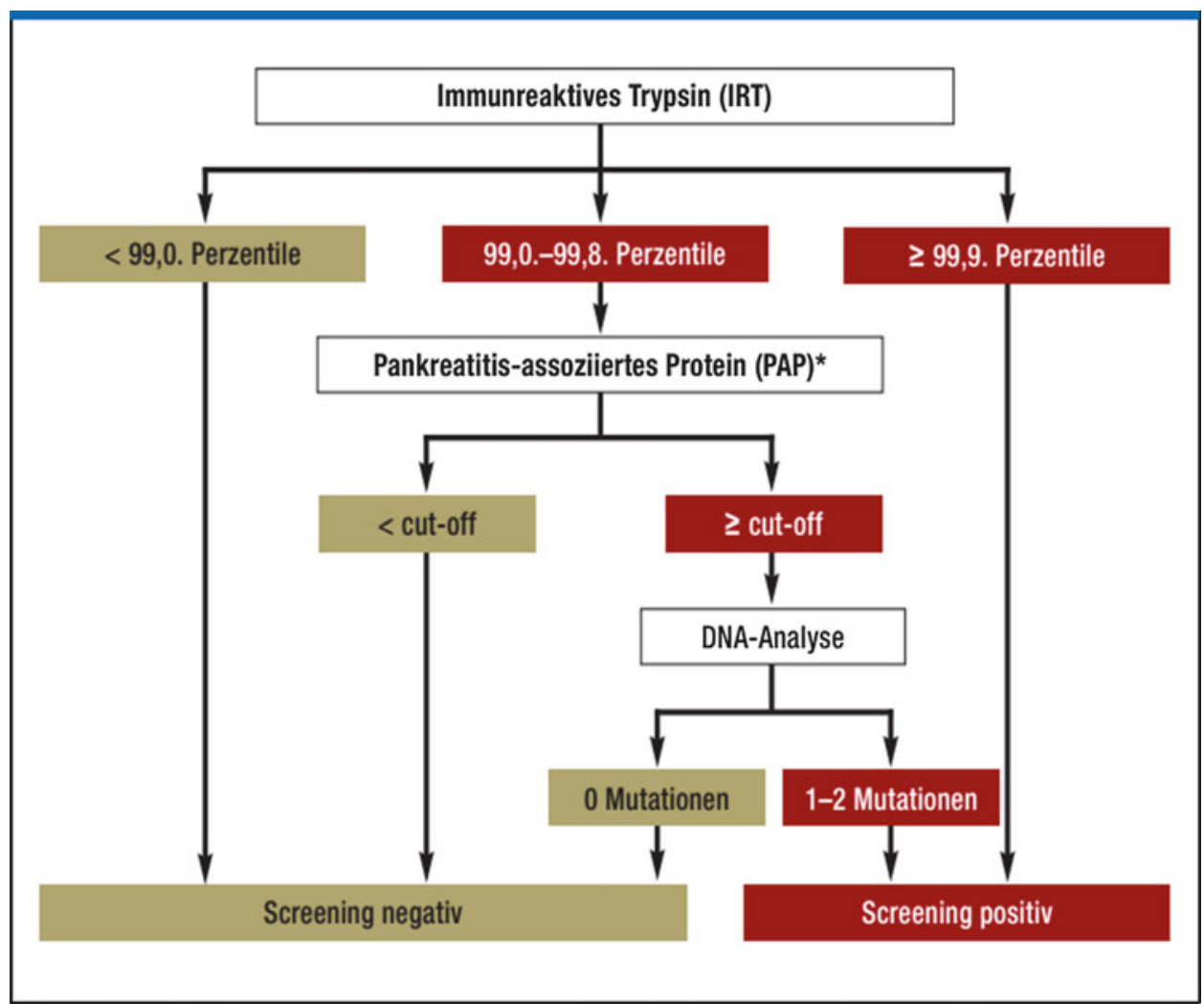

die Dauerhaftigkeit der Entzündung, für die anhaltende proinflammatorische Reaktion werden CF-spezifische Veränderungen an Makrophagen diskutiert: In Ermangelung suffizienter funktionstüchtiger CFTR-Moleküle findet der Switch vom M1- auf den M2-Makrophagen im Blut nicht statt. Fehlt es an M2-Makrophagen kommt es nicht zur Auflösung der Entzündung. Andererseits werden bei Pseudomonas-aeruginosaInfizierten vermehrt M2-Makrophagen in der humanen BAL (bronchoalveoläre Lavage) beschrieben.

Zusammenfassend ist davon auszugehen, dass es infolge des CFTR-Mangels zu weiteren Imbalancen in verschiedenen pro- und anti-inflammatorischen Prozessen kommt:

a. Lipide: Im Arachidonstoffwechsel verschiebt sich das Verhältnis von Arachidonsäure/Docosahexaensäure zu Ungunsten der Docosahexaensäure. Ebenso finden sich steigende zelluläre Ceramidspiegel. Beide gelten als proinflammatorisch.

b. Weitere Stoffwechselwege: Verminderte NO-Synthese in den unteren Atemwegen, gesteigerte Differenzierung der T-Lymphozyten zum Th17-Phänotyp, verminderte Efferozytose (Abräumen von absterbenden Zellen [apoptotisch/nekrotisch] durch phagozytierende Zellen mit der Folge der Persistenz der Proinflammation), abnormales Nrf2-Signal mit der Folge von inadäquaten antiinflammatorischen und antioxidativen Reaktionen, auffällige TLR5-
Immunantworten und gesteigerte MAPK- und NFkB-Aktivität.

Sekundäre inflammatorische Defekte in den CF-Atemwegen führen zu einer chronischen Inflammation ohne Auflösung: Neutrophile Granulozyten (polymorphonuclear leukocytes, PMNs) migrieren als erste in die Lunge. Auf der einen Seite dienen sie der Abwehr gegen Bakterien und Pilze. Anderseits können sie möglicherweise über die Freisetzung von Oxidanzien und Proteasen das Lungengewebe schädigen. Erreicht die Menge an Pathogenen eine kritische Größe oder schützen sich die Erreger durch Biofilme, werden die Neutrophilen unfähig zu einer effizienten Phagozytose. Extrazelluläre Abwehrmechanismen wie die Neutrophil-extracellular-trap(NET)-Bildung und die Freisetzung von Defensinen und Proteasen setzen ein.

\section{Klinische Symptome und Verlauf}

Kinder mit chronisch-persistierendem Husten, obstruktiver Bronchitis oder rezidivierenden Pneumonien sind verdächtig auf eine pulmonale Verlaufsform der Mukoviszidose. Patienten mit einer milden CF präsentieren sich z. T. auch nur mit einer chronischen Sinusitis oder nasalen Polypen.

Die Auskultation spiegelt oben genannte Symptome wider: Rasselgeräusche, initial feinblasig bei Pneumonie, im fortgeschrittenen Stadium grobblasig bei Bronchiektasen. Diese finden sich bereits bei einem Drittel der Patienten im 
CT-Thorax in den ersten Lebensmonaten. In einer durch Neugeborenenscreening diagnostizierten Säuglingskohorte (ARREST-CF) gelang es bei (klinisch nur zur 15,8 \% kranken) Säuglingen bereits im Alter von weniger als 4 Monaten schon bei $80 \%$ Auffälligkeiten in der CT der Lunge nachzuweisen.

Bei obstruktiver Symptomatik finden sich Giemen und Brummen. Im Zuge der fortschreitenden Obstruktion und Überblähung können die Patienten einen Fassthorax entwickeln. Als Ausdruck der chronischen Hypoxie finden sich Uhrglasnägel und Trommelschlegelfinger.

Klassische Zeichen der pulmonalen Exazerbation (modifizierte Fuchs-Kriterien nach Bilton) sind:

- Veränderungen der Sputummenge oder -farbe,

- vermehrter Husten,

- zunehmende Abgeschlagenheit und Krankheitsgefühl,

- signifikanter Gewichtsverlust,

- Abfall der Lungenfunktion um mehr als $10 \%$ und/oder Zunahme der radiologischen Veränderungen,

- zunehmende Atemnot.

Sind mindestens 2 Kriterien erfüllt, ist dies als Exazerbation zu werten. Dies erfordert eine zusätzliche Antibiotikatherapie. Die Epidemiologic Study of Cystic Fibrosis (ECFS) konnte zeigen, dass bei Kindern zwischen dem 6. und 17. Lebensjahr durch eine stationäre antibiotische Therapie die Chance den Verlust an Lungenfunktion wieder einzuholen wesentlich höher ist, als durch ambulante Behandlung. Allerdings finden sich bei Kindern (oft noch ohne Pseudomonas aeruginosa) auch häufig nur mildere Symptome (Husten, Giemen, Fieber, Rhinorrhö) bei (meist viral) getriggerten Exazerbationen.

\subsection{Diagnostik}

Folgende Diagnostik sollte in regelmäßigen Abständen und bei einem Verdacht auf pulmonale Exazerbation erfolgen.

\section{Mikrobiologische Diagnostik}

Eine mikrobiologische Diagnostik (Rachenabstriche oder Sputum) sollte bei chronisch Besiedelten mindestens alle 3 Monate erfolgen. Für Patienten mit bisher negativen Befunde sind, bei Kleinkindern alle 2-4 Wochen und bei Erwachsenen alle 3 Monate, besser 6- bis 8-wöchige Kontrollen zu empfehlen. Die deutsche Leitlinie sieht mindestens 6 Untersuchung/Jahr vor. Ist der Patient nicht in der Lage Sputum abzuhusten, sollte neben tiefen Rachenabstrichen (negativ-prädiktiver Wert $95 \%$, positiv-prädiktiver Wert $44 \%$ ) auch induziertes Sputum gewonnen werden. Die Gewinnung erfolgt durch Abhusten nach Inhalation von 3bis 7-prozentiger $\mathrm{NaCl}$-Lösung $(3 \mathrm{ml})$. Um einen Broncho- spasmus zu verhindern, sollte vorher protektiv mit Sultanol inhaliert werden. Nasale Abstriche oder Lavage (2-mal $10 \mathrm{ml}$ $\mathrm{NaCl}$ 0,9\%) sind zu diskutieren. Weitere diagnostische Bausteine sind Pseudomonas-Antikörper bei klinischem Verdacht und mangelndem mikrobiologischen Nachweis (bei negativen Patienten 1-mal/Jahr empfohlen). Invasive Diagnostik, wie die Gewinnung einer bronchoalveolären Lavage, sollte anderweitig diagnostisch nicht zu klärenden pulmonalen Exazerbationen vorbehalten sein.

\section{Lungenfunktionstests (LFT) \\ Säuglings- und Vorschulalter}

Nach Einführung des Neugeborenenscreening beginnt die Therapie bei Diagnosestellung im Säuglingsalter. Daraus ergibt sich die Notwendigkeit valider Biomarker auch für diese Altersklasse.

Raised volume rapid thoracoabdominal compression technique (RVRTC-Technik) Bei Säuglingen (diagnostiziert über Neugeborenenscreening) findet sich in den ersten 6 Monaten eine Verminderung (FEV 0,5 z-Score wie FVC und FEF 75) der LFT, die aber reversibel sein kann bis zum 2. Lebensjahr.

Bei Infektion findet sich ein inverses Verhältnis von LFT zur neutrophilen Inflammation und der Bakteriendichte. Höherer Abfall der Lungenfunktion findet sich bei Infektion mit Staph. aureus und Pseudomonas aeruginosa.

Multiple breath washout (MBW) Das FEV1 wird durch Veränderungen der großen Atemwege beeinflusst. Doch die ersten Veränderungen im Säuglings- und Kleinkindesalter bei $\mathrm{CF}$ sind strukturelle Veränderungen und Entzündung in den peripheren Atemwegen. Die MBW dient dem Nachweis von Auffälligkeiten der peripheren Atemwege $(<2 \mathrm{~mm})$ distal der Bronchusgeneration 8. Der Lung clearance index (LCI) 2,5 \% (Messgröße für Ventilationsinhomogenität) und die funktionelle Residualkapazität (FRC; Marker für Überblähung) sind zu 41,5\% bereits kurz nach der Geburt auffällig. Auch im Alter von 2 Jahren fanden sich noch 0,81 höhere z-Scores (bzw. bei $15 \%$ der CF-Patienten) als bei Kontrollen. In der longitudinalen Beobachtung findet sich eine Normalisierung der individuellen Werte.

In den ersten 2 Lebensjahren ist der LCI nicht geeignet, um Hinweise auf radiologisch-strukturelle Veränderungen zu geben. Auffällige LCI-Werte im Vorschulalter haben einen besseren prädiktiven Wert für den Verlauf des FEV1 im Schulalter (als das im Vorschulalter gemessene FEV1). Die britischen NICE-guidelines empfehlen eine LCI-Messung bei Personen mit unauffälligem FEV1.

$\mathrm{Ab}$ dem 4-5. Lebensjahr soll eine routinemäßige Lungenfunktionsprüfung mittels Bodyplethysmographie und Spirometrie erfolgen. 
Spirometrie im Vorschulalter Es finden sich milde Veränderungen im Vorschulalter. Auch sind diese in jener Altersklasse sehr variabel. Der Anteil auffälliger Spirometriebefunde (z-Score $\leq-1,96)$ wird mit 9-36 \% (je nach Parameter und Kohorte) beziffert.

Spezifischer Atemwegswiderstand (sRaw) Der sRaw ist in dieser Altersklasse signifikant erhöht im Vergleich zu Gesunden. Diese Messgröße erfasst besser eine frühe Lungenpathologie als die Spirometrie, allerdings weniger gut als der LCI.

\section{Schulalter}

Für diese Altersgruppe bieten sich folgende Verfahren an.

Spirometrie und Bodyplethysmografie Einer der ersten Auffälligkeiten ist eine Überblähung durch vermehrtes intrathorakales Gasvolumen (ITGV) oder Residualvolumen (RV). Spirometrische Auffälligkeiten finden sich in den kleinen Atemwegen: Die Flussvolumenkurve zeigt verminderte Werte für den Maximum expiratory flow bei 25, 50 und 75 \% (MEF 25-75 \%) der forcierten Vitalkapazität (FVC).

Der wichtigste Parameter für den klinischen Verlauf bzw. die Prognose ist das FEV1. In der Regel geht man von 1,3 \% Abfall/Jahr durch chronische Entzündungen sowie Exazerbationen aus.

Pulmonale Exazerbationen führen bei einem Viertel der Patienten zu einem persistierenden Verlust an Lungenfunktion.

Multiple breath washout (MBW) Für den Einsatz dieser Methode für Entscheidungen im Rahmen der klinischen Routine gibt es derzeit keine klare Empfehlung.

Stickoxid im Atemexhalat Im Gegensatz zum allergischen Asthma bronchiale finden sich nicht erhöhte, sondern erniedrigte Stickoxid(NO)-Werte im bronchialen wie nasalen Atemexhalat.

Pulsoximetrie Die Pulsoximetrie zeigt, abgesehen von pulmonalen Exazerbationen, lange unauffällige Werte. Erste Auffälligkeiten finden sich bei körperlicher Belastung oder im Schlaf. Erst im fortgeschrittenen Stadium finden sich Auffälligkeiten in der Blutgasanalyse. Folge der chronischen Hypoxie kann ein Cor pulmonale sein. Daher sollte eine Echokardiografie auf pulmonalen Hypertonus in regelmäßigen Abständen erfolgen.

\section{Radiologische Diagnostik}

\section{Röntgenthorax}

Auffälligkeiten im Röntgenthorax lassen sich bereits im 1. Lebensjahr nachweisen. Die europäischen Leitlinien für die ersten 2 Lebensjahre empfehlen einen Röntgenthorax bei Diagnosestellung und persistierenden respiratorischen Symp- tomen trotz adäquater Therapie. Die britischen NICELeitlinien für $\mathrm{CF}$ empfehlen jährliche Röntgenthorax-Untersuchungen auch bei asymptomatischen CF-Patienten ohne auf die Altersgruppe einzugehen.

Erste Veränderungen sind Zeichen der Überblähung. Im Verlauf finden sich Ringschatten (Bronchialwandverdickungen und Bronchiektasen, Abb. 4a). Im Spätstadium der CF kommt es zur Zystenbildung, Fortschreiten der Bronchiektasen sowie Zeichen der pulmonalarteriellen Drucksteigerung (Kalibersprung von zentralen zu Segmentlungenarterien).

Zur vergleichenden Beurteilung wird der ChrispinNorman-Score des Röntgenthorax favorisiert. Hierbei wird nach Quadranten getrennt das Ausmaß von Fleckschatten, Überblähung, Bronchialwandverdickung und interstitiellen Streifen beurteilt. Die maximale Punktzahl beträgt 38. Eine gesunde Lunge würde mit 0 Punkten beschrieben. Bei Kindern mit $\mathrm{CF}$ ist mit einer Zunahme von 1-2 Punkten pro Lebensjahr zu rechnen.

\section{High-resolution Computertomografie (HRCT)}

Sensitiver als konventionelle Röntgenaufnahmen sowie die Lungenfunktion ist die high-resolution CT (HRCT). Hier können Bronchialwandverdickungen, Schleimpfropfen, Belüftungsinhomogenitäten und Bronchiektasen zu einem Zeitpunkt nachgewiesen werden, zu dem sie im konventionellen Röntgenbild nicht sichtbar sind (Abb. 4b, c). Auch Tree-inbud-Phänomene (Verdichtungen entsprechend exsudativer bronchiolärer Erweiterungen wie sie im Rahmen von chronischer Pseudomonas-aeruginosa-Infektion oder bei allergischbronchopulmonaler Aspergillose [ABPA] auftreten) lassen sich hiermit darstellen (Abb. 4d).

Sie gilt als Goldstandard, um anatomische bzw. strukturelle Veränderungen der Lunge bei $\mathrm{CF}$ zu beurteilen. Am besten korreliert der Score nach Gustafson (gefolgt vom Brody-Score) mit spirometrischen Parametern.

\section{Magnetresonanztomografie}

Aufgrund der hohen Strahlenbelastung der HRCT findet die Magnetresonanzstomografie (MRT) zunehmende Beachtung. Ein Vorteil ist die Möglichkeit dabei die Lungenfunktion in Echtzeit zu beobachten, im Sinne einer sensitiven und genaueren Erfassung des Fortschreitens der Erkrankung. Auch kann die MRT zusätzliche Information zu Perfusion geben und ist hier auch dem LCI überlegen. Kritisch sind derzeit die geringe räumliche Auflösung und das Fehlen eines objektiven Scoring-Systems.

\subsection{Therapie}

\section{Wichtige Erreger und deren Therapie}

Während in den ersten Lebensjahren Bakterien wie Haemophilus influenzae und Staphylococcus aureus (43\% chroni- 

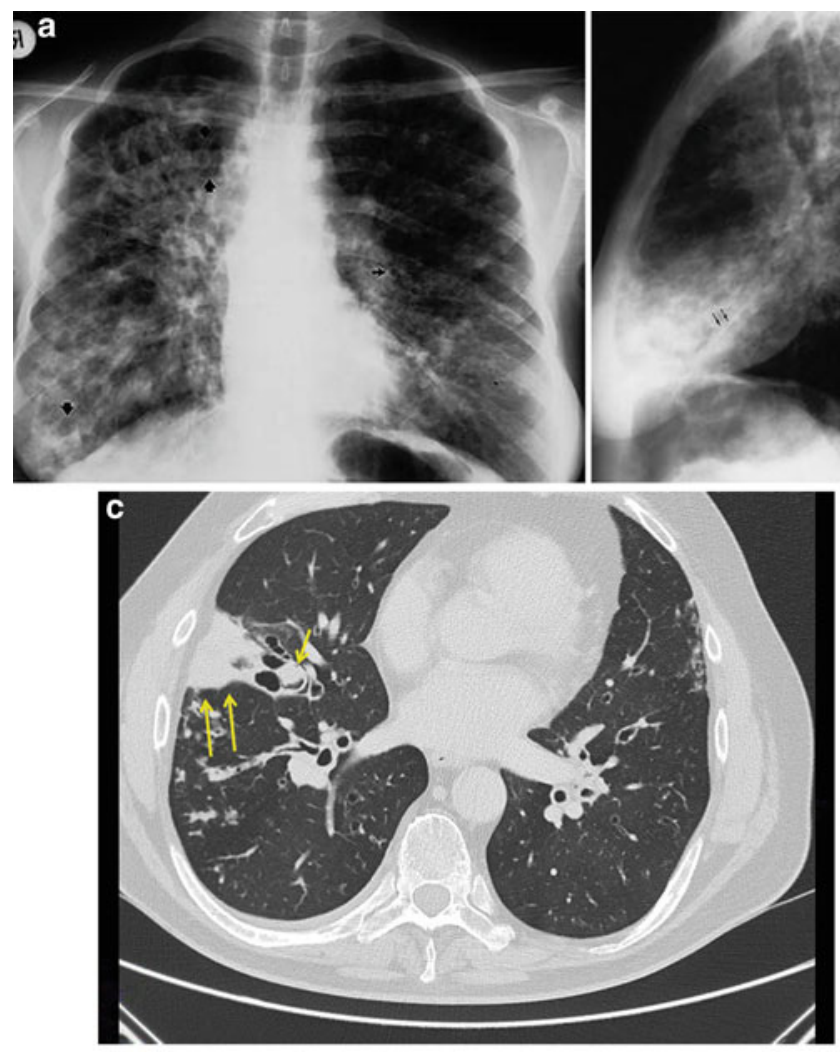

Abb. 4 a End-stage-Lunge. a.-p.-Aufnahme: peribronchiale Verdickungen (kleiner Pfeil), Ringschatten (dicke Pfeile) als Hinweis auf Bullae, Pneumatozele oder Abszessbildung; Seitenbild: vergrößerter Retrosternalraum (Überblähung und Krümmung des Sternums), längere Pfeile markieren Interlobium. Auf beiden Abbildungen deutliche Wabenbildungen (17 Jahre alte weibliche Patientin). b Bronchialwandverdickungen (Kreuz mit Einzelpfeil) und zylindrische Bronchiektasen (Doppelpfeile)

sche Besiedlung im 10. Lebensjahr) im Vordergrund stehen, findet sich im 10. Lebensjahr bei $12 \%$ eine chronische Pseudomonas-aeruginosa-Besiedlung. Weitere für den pulmonalen Verlauf relevante Bakterien sind Burkholderia cepacia, Stenotrophomonas maltophilia, methicillinresistente Staphylokokken (MRSA), Achromobacter xylooxidans und atypische Mykobakterien. Mit einem zunehmenden Einsatz von inhalativen Antibiotika und einer längeren Überlebenszeit finden sich auch vermehrt klinisch relevante Infektionen mit Pilzen wie Aspergillus fumigatus, Candida albicans und Scedosporium species.

\section{Pseudomonas aeruginosa}

Pseudomonas aeruginosa ist der wichtigste pulmonale Erreger bei CF: $53 \%$ der deutschen erwachsenen CF-Patienten sind mit P. aeruginosa infiziert. Auch bei Säuglingen wurde bei $5 \% \mathrm{P}$. aeruginosa nachgewiesen, welche über Neugeborenenscreening identifiziert wurden. einer 24 jährigen Patientin mit einer chronischen Pseudomonas-aeruginosa-Infektion. c Schleimverlegter Bronchus (Einzelpfeil) und Infiltrat (Doppelpfeil) bei Exazerbation einer chronischen Pseudomonas-aeruginosa-Infektion. d Tree-in-bud-Phänomen (Pfeile) bei einer 24-jährigen Patientin mit einer chronischen Pseudomonas-aeruginosa-Infektion und allergisch-bronchopulmonaler Aspergillose (ABPA)

Infektionen mit $\mathrm{P}$. aeruginosa führen zu einer gesteigerten Morbidität, einem schnellerem Verlust an Lungenfunktion (ca. $2 \% / \mathrm{Jahr}$ ). Ca. $90 \%$ dieser Patienten werden an den Folgen ihrer pulmonalen Pathologie sterben.

Aufgrund des Nachweises von P.-aeruginosa-Klonen ist davon auszugehen, dass die Übertragung von Patient zu Patient eine wichtige Rolle spielt und nicht ein aus der Umwelt individuell erworbener Keim. Daher sind Mukoviszidosepatienten im ambulanten Bereich streng zu trennen. Im stationären Bereich ist ein Einzelzimmer mit eigener sanitärer Versorgung zu fordern.

Pseudomonas aeruginosa verfügt über adaptive Mechanismen, die es dem Keim ermöglichen, in den Atemwegen trotz der Abwehr des Wirtes und antibiotischer Therapie zu überleben. Der Sauerstoffmangel infolge der Schleimlast auf den Atemwegen triggert den Wechsel vom nichtmukoiden zum mukoiden Phänotyp bei P. aeruginosa. Probleme des mukoiden Phänotyps sind die Resistenz gegen die Abwehr des Wirtes. Die durch sie gebildeten Biofilme sind schwer mit 
Antibiotika zu behandeln. Unter dem Schutz eines Biofilmes ist $P$. aeruginosa in der Lage zu wachsen. So kann er sich der Abwehr des Wirtes entziehen und eine antibiotische Therapie tolerieren.

Der Verlauf der Infektion lässt sich in 3 Phasen einteilen:

a. keine Infektion,

b. intermittierende Infektion und

c. chronische Infektion.

Eine chronische Infektion liegt vor, wenn sich in $>50 \%$ der untersuchten mikrobiologischen Proben in den letzten 12 Monaten P. aeruginosa nachweisen lässt. Eine intermittierende Infektion liegt vor, wenn $<50 \%$ der Proben auf P. aeruginosa positiv waren.

In der Lunge wird die konduktive Zone (Trachea bis terminale Bronchiolen) mit anaeroben Sputum und die aerobe respiratorische Zone (respiratorische Bronchiolen bis zu den Alveolen) unterschieden. In der respiratorischen Zone finden sich keine Zilien, keine Becherzellen und keine submukösen Drüsen. Das Abwehrsystem besteht aus Alveolarmakrophagen und Defensinen. Das gesamte venöse Blut passiert die Alveloarkapillaren. Hier findet sich nur eine sehr dünne Barriere zwischen Luft und Blut. In der konduktiven Zone finden sich Zilien, Becherzellen und submuköse Drüsen. Inhalative Antibiotika erreichen die konduktive Zone, aber nur in sehr geringen $\mathrm{Ma}$ die respiratorische Zone. Systemisch (oral oder intravenös) verabreichte Antibiotika finden sich in hohem Maße in Lungengewebe, geringer im Sputum. Da P. aeruginosa zur Infektion der konduktiven wie der respiratorischen Zone führt, sollten Patienten mit einer kombinierten Therapie aus systemischen und inhalativen Antibiotika behandelt werden.

Die deutsche Leitlinie empfiehlt (bei einer i.v.-Therapie bei chronischer Besiedlung) nicht generell eine zeitgleiche Antibiotikainhalation mangels Evidenz für einen zusätzlichen Benefit. Sie verweist auf die Problematik des Bronchospasmus bei Antibiotikainhalation und eine vermehrte Nephrotoxizität bei i.v.- und inhalativer Gabe von Tobramycin.

Erste und intermittierende Infektion Die deutsche Leitlinie empfiehlt eine Therapie a) mit inhalativem Tobramycin (2-mal $300 \mathrm{mg} /$ die) über 4 Wochen oder b) das dänische Schema bei Erstinfektion: Colistin ad inhal (2-mal 1 Mio. $\mathrm{IE} / \mathrm{die})$ und Ciprofloxacin $(25-50 \mathrm{mg})$ p.o. in $2 \mathrm{ED}$ über 3 Wochen. Bei erneuter Infektion wird das Schema wiederholt, aber Colisitin auf 3-mal 2 Mio. IE/Tag erhöht, bei 3. Nachweis von P. aeruginosa innerhalb von 6 Monaten erfolgt oben genannte Therapie über 3 Monate.

Ist der 1. Eradikationszyklus erfolglos, sollte die i.v.Therapie über 14 Tage durchgeführt werden oder eine inhalative Tobraymcin-Therapie (2-mal $300 \mathrm{mg} / \mathrm{Tag}$ ) über 4 Wochen bzw. der 2. Zyklus des dänischen Schemas.
Wenn die Inhalation von Antibiotika nicht möglich ist, sollte nach deutscher Leitlinie eine intravenöse Kombinationstherapie erfolgen. Dieses gilt auch, wenn der Erstnachweis mit einer pulmonalen Exazerbation einhergeht (bzw. i.v.-Therapie gefolgt von inhalativem Antibiotikum).

Eine Eradikation war erfolgreich, wenn 3 aufeinanderfolgende respiratorische Proben in einem Gesamtzeitraum von 6 Monaten negativ sind (Maximalabstand zwischen den Proben 8 Wochen). Tiefe Rachenabstriche sind weniger aussagekräftig als Sputumuntersuchungen oder BAL. Daher empfiehlt sich bei 3 negativen Rachenabstrichen die Bestimmung von P.-aeruginosa-Antikörpern nach 3 Monaten.

Intravenöse Antibiotikatherapie Bei mangelhafter Eradikation kann eine intravenöse Antibiotikatherapie mit 2 Antibiotika aus verschiedenen Substanzgruppen (klassisch: Ceftazidim und Tobramycin) erfolgen. Bei Erstnachweis sollte eine Empfindlichkeitstestung des Erregers erfolgen. Die Therapiedauer liegt bei 14 Tagen. Klare Richtlinien zur Therapiedauer liegen nicht vor. Eine Therapiedauer von weniger als 10 Tagen birgt das Risiko der nicht ausreichenden Infektionsbekämpfung. Mehr als 21 Tage intravenöse Behandlung sind problematisch, da das Risiko einer allergischen Reaktion mit zunehmender Therapiedauer steigt. Aufgrund der höheren Clearance infolge gesteigerter renaler und nonrenaler Elimination sind bei CF höhere Dosierungen erforderlich (Tab. 1).

Chronische Infektion Eine orale Monotherapie (Ciprofloxacin oder Levofloxacin) über 2-3 Wochen ist wirksam. Bei Erwachsenen ist sie gleich wirksam wie eine intravenöse Kombinationstherapie. Orale Monotherapien können mit inhalativen oder intravenöser Antibiotikatherpie kombiniert werden. Die Frequenz einer i.v.-Therapie ist vom Schweregrad und der Zunahme der Symptome abhängig. Laut deutscher Leitlinie ist eine Therapie in regelmäßigen Intervallen einer symptomorientierten Therapie nicht überlegen. In Bezug auf Heim- vs. stationärer i.v-Therapie kann die Therapie bei stabilen Patienten und gesicherten sozialen Strukturen zu Hause durchgeführt werden. Ein Beginn unter stationären Bedingungen wird empfohlen, um die Verträglichkeit der Medikamente, die Medikamentenspiegel und das Ansprechen der Therapie zu prüfen.

Sofern eine chronische P.-aeruginosa-Infektion vorliegt, profitieren Patienten von einer Therapie mit inhalativen Antibiotika. Sie führt zur Verbesserung klinischer Symptome, der Lebensqualität, Verbesserung der Lungenfunktion und Abnahme der Exazerbationsfrequenz. Folgende Wirkstoffgruppen stehen zur Verfügung: Aztreonamlysinat, ColistinmethtatNatrium, Tobramycin, Levofloxacin. Zu den Dosierungen sei auf die deutsche Leitlinie (http://www.awmf.org/uploads/tx szleitlinien/020-0181_S3_Mukoviszidose_Modul_2_2017-0801.pdf) verwiesen. Tobramycin und Colistin sind inzwischen 
Tab. 1 Europäische Dosis-Empfehlung der S3-Leitlinie (mod. nach Schwarz et al. 2017)

\begin{tabular}{|c|c|c|}
\hline Antibiotika & Dosis & Maximaldosis \\
\hline \multicolumn{3}{|l|}{ Beta-Lactam-Antibiotika } \\
\hline Aztreonam & $150 \mathrm{mg} / \mathrm{kg} / \mathrm{Tag} ; 6$ stdl. & $8 \mathrm{~g} / \mathrm{Tag}$ \\
\hline \multicolumn{3}{|l|}{ Cephalosporine } \\
\hline Ceftazidim & $150-250 \mathrm{mg} / \mathrm{kg} / \mathrm{Tag} ; 6-8 \mathrm{stdl}$. & $12 \mathrm{~g} / \mathrm{Tag}$ \\
\hline Cefepim & $100-150 \mathrm{mg} / \mathrm{kg} / \mathrm{Tag} ; 6-8 \mathrm{stdl}$. & $6 \mathrm{~g} / \mathrm{Tag}$ \\
\hline \multicolumn{3}{|l|}{ Carbapeneme } \\
\hline Imipenem & 50-100 mg/kg/Tag; 6 stdl. (schnelle Resistenzentwicklung) & $4 \mathrm{~g} / \mathrm{Tag}$ \\
\hline Meropenem & $60-120 \mathrm{mg} / \mathrm{kg} / \mathrm{Tag} ; 8$ stdl. & $6 \mathrm{~g} / \mathrm{Tag}$ \\
\hline \multicolumn{3}{|l|}{ Penicillline } \\
\hline Piperacillin-Tazobactam* & $240-400 \mathrm{mg} / \mathrm{kg} / \mathrm{Tag} ; 4$ stdl. & 12-16 g/Tag (Piperacillin-Komponente) \\
\hline Ticarcillin-Clavulanat & $500-750 \mathrm{mg} / \mathrm{kg} / \mathrm{Tag} ; 6$ stdl. & $30 \mathrm{~g} /$ Tag (Ticarcillin-Komponente) \\
\hline \multicolumn{3}{|l|}{ Aminoglykoside } \\
\hline Amikacin & $30 \mathrm{mg} / \mathrm{kg} /$ Tag; Einzeldosis & $\begin{array}{l}\text { Spitzenspiegel } 80-120 \mathrm{mg} / 1 \\
\text { Talspiegel }<1 \mathrm{mg} / 1\end{array}$ \\
\hline Tobramycin & $10 \mathrm{mg} / \mathrm{kg} / \mathrm{Tag}$; Einzeldosis & $\begin{array}{l}\text { Spitzenspiegel } 20-40 \mathrm{mg} / \mathrm{l} \\
\text { Talspiegel }<1 \mathrm{mg} / 1\end{array}$ \\
\hline Gentamicin & Nicht für Routine-Gebrauch empfohlen & \\
\hline \multicolumn{3}{|l|}{ Fluorchinolone } \\
\hline Ciprofloxacin (oral) & $30 \mathrm{mg} / \mathrm{kg} / \mathrm{Tag} ; 12$ stündlich & $1,5-2,25 \mathrm{~g} / \mathrm{Tag}$ \\
\hline Ciprofloxacin (i.v.) & $30 \mathrm{mg} / \mathrm{kg} / \mathrm{Tag} ; 8$ stündlich & $1,2 \mathrm{~g} / \mathrm{Tag}$ \\
\hline Levofloxacin & Unzureichende Evidenz & \\
\hline \multicolumn{3}{|l|}{ Andere } \\
\hline Colistimethat-Natrium** & $\begin{array}{l}2,5-5 \mathrm{mg} / \mathrm{kg} / \mathrm{Tag} \\
75.000 \mathrm{IU} / \mathrm{kg} / \mathrm{Tag}\end{array}$ & $\begin{array}{l}480 \mathrm{mg} / \mathrm{Tag} \\
6 \mathrm{Mio.} \text { IU/Tag }\end{array}$ \\
\hline
\end{tabular}

*Empfehlungen der FDA/CFF [Food and Drug Administration/Cystic Fibrosis Foundation]; **Empfehlungen FDA/UK-Trust

auch als Trockeninhalat verfügbar. Vorteile sind die Zeitersparnis und damit eine bessere Compliance.

Impfungen gegen P. aeruginosa können nicht empfohlen werden.

Obere Atemwege Bei Dauerbesiedlung der Atemwege kann 1-mal/Jahr die Kolonisierung der oberen Atemwege untersucht werden mit einer Nasenspülung von $10 \mathrm{ml} \mathrm{NaCl}$ $0,9 \%$. Sofern nicht toleriert, sind Nasenabstriche empfohlen. Vor einer Lungentransplantation muss die sinonasale Situation mikrobiologisch untersucht werden. Sinonasale Antibiotikainhalationen sind bei chronischer Besiedlung indiziert. Auch eine isolierte wiederholte Besiedlung mit P. aeruginosa sollte mittels sinonasaler Antibiotikainhalation oder OP (mit anschließender Antibiotika-Lavage oder -Inhalation) eradiziert werden. Die deutsche Leitlinie empfiehlt sinonasale Mukolytika-Inhalationen bei entsprechenden Beschwerden. Topische Steroide können bei Obstruktionen und Polypen angewendet werden.

\section{Burkholderia cepacia}

Der Burkholderia-cepacia-Komplex umfasst 9 Spezies, unter anderem B. cepacia genomvar I und III, B. multivorans, B. cenocepacia, B. stabilis und B. vietnamiensis. Die Prävalenz der chronischen Infektion liegt bei 0,9\% im Kindesalter in Deutschland. Einmalig konnte der Keim 2016 bei 1,4\% der unter 18-Jährigen nachgewiesen werden. Die Übertragung zwischen Patienten ist nicht selten, daher ist auf eine strikte Trennung zu achten. Klinisch findet sich eine massive Verschlechterung der Lungenfunktion bei Bakteriämie. Aufgrund der Multiresistenz des Erregers ist die Eradikation oft nicht erfolgreich. Ziel der Therapie ist daher meist nur, die Zahl der Bakterien zu vermindern. Erfolgversprechend scheint eine Dreifachtherapie mit Tobramycin, Meropenem und einem 3. Antibiotikum. Bei multiresistenten Stämmen kann eine Kombination mit Moxifloxacin, Ceftazidim und niedrig dosiertem Colistin erfolgreich sein. Für die Eradikation wie bei pulmonalen Exazerbationen sollte eine In-vitroEmpfindlichkeitstestung erfolgen.

\section{Methicillin-resistente Staphylokokken (MRSA)}

In Deutschland betrug die Prävalenz im Jahr 2016 5,3\% bei allen CF-Patienten, $4 \%$ für Kinder ( $<18$ Jahren). Die klinische Relevanz von MRSA-Infektionen bei CF-Patienten bleibt kontrovers.

Die Behandlungserfolge der Eradikationsversuche sind bei ansteigender Resistenz auf gängige Antibiotika (sofern sensibel, Rifampicin + Trimethoprim-Sulfmethoxazol, Linezolid, Vancomycin inhalativ) problematisch. Am erfolgreichsten sind Regime mit 2 oralen Antibiotika in Kombination mit inhalativen Vancomycin. 
Eine evidenzbasierte Therapieindikation wie Behandlungsschemata bestehen nicht. Als erfolgreich hat sich folgendes Schema erwiesen: Trimethoprim-Sulfmethoxazol TMP in Kombination mit Rifampicin über 2 Wochen, zusätzlich erhalten die Patienten zur Dekolonisation eine topische Therapie (Chlorhexidin-Mundspülung und Hautdesinfektion, nasal Mupirocin).

Ein erfolgreiches dreistufiges Therapieschema besteht aus:

a. i.v.-Doppelantibiose (Teicoplanin oder Vancomycin kombiniert mit Fosfomycin oder Linezolid oder Tobramycin über 3 Wochen) mit topischer Antibiotikagabe über 5 Tage gefolgt von

b. orale Doppelantibiose über 6 Wochen nach Resistogramm, danach

c. Inhalation über 6 Wochen mit Vancomycin.

Die 3 Jahreseradikationsrate lag bei $84 \%$.

Bei pulmonaler Exazerbation sind Vancomycin oder Linezolid empfohlen. Sofern P. aeruginosa mit potenziell nephrotoxischen Medikamenten mit behandelt werden, ist Linezolid der Vorzug zu geben.

Wichtig ist es die Hygienestandards strikt einzuhalten bzw. die entsprechende Trennung der Patienten.

Es gibt bisher keine standardisierte Definition der chronischen MRSA-Infektion. Es wurden mindestens 3 positive Kulturen in den letzten 6-12 Monaten in diesem Sinne gewertet.

\section{Stenotrophomonas maltophilia}

Die Prävalenz liegt bei $10,7 \%$ bei Kindern in Deutschland. Chronisch besiedelt sind 2,6\%. Kontrovers ist die Diskussion, ob eine chronische S.-maltophilia-Infektion zum Verlust an Lungenfunktion führt. Bei pulmonaler Exazerbation und Nachweis von S. maltophilia ist eine Therapie mit Flurochinolonen, Tetrazyklinen, oder Trimethoprim-Sulfmethoxazol zu erwägen. Eine Resistenztestung und eine Kombinationstherapie ist zu diskutieren. Evidenz für die Effektivität einer antibiotischen Therapie steht noch aus.

\section{Nichttuberkulöse Mykobakterien}

Diese finden sich bei ca. 5,6 \% der CF-Patienten unter 18 Jahren in Deutschland. CF-relevant sind M.-avium-Komplex (MAC) und M.-abcessus-Komplex (MABSC).

Zwei klinische Kriterien müssen erfüllt sein:

a. pulmonale Symptome mit nodulären/kavitären Trübungen (opacity) im Röntgenthorax oder HRCT mit multifokalen Bronchiektasen und multiplen kleinen Knoten,

b. andere Ursachen müssen ausgeschlossen sein.
Mindestens eines der mikrobiologischen Kriterien muss erfüllt sein:

a. 2 positive Sputumkulturen an 2 unterschiedlichen Zeitpunkten,

b. positive Kulturen aus mindestens 1 bronchoalveolären Lavage,

c. Histopathologie vereinbar mit Mykobakterien in der Lungenbiopsie und positive Kultur aus Biopsie, Sputum oder Spülflüssigkeit.

Die Behandlung bei pulmonaler Infektion mit MABSC sieht eine tägliche Gabe mit Azithromycin in Kombination mit einer 3- bis 12-wöchigen i.v.-Therapie mit Amikacin und eines der folgenden Antibiotika vor: Tigecylin, Imipenem oder Cefoxitin. Es folgt eine tägliche Behandlung mit inhalativem Amikacin, Azithromycin p.o. und 2-3 weiteren Antibiotika (Minocyclin, Clofazimin, Moxifloxacin und Linezolid) p.o. über maximal 14 Wochen.

Infektionen mit Clarithromycin-sensiblen MAC-Komplex werden mit einer Kombination von Azithromycin, Ethambutol, Rifampicin p.o. über maximal 17 Wochen behandelt.

Die US/Europäische Consensus Empfehlung sieht 1-mal/ Jahr Sputum-Untersuchungen auf atypische Mykobakterien bei klinisch stabilen Patienten die Sputum expektorieren können vor. Kann kein Sputum spontan expektoriert werden und finden sich keine klinischen Hinweise auf eine NTM-Infektion, ist diese Untersuchung nicht notwendig.

\section{Staphylococcus aureus}

Eine Erstinfektion sollte über 2-4 Wochen mit einer Kombination von Dicloxacillin und Fusidinsäure oder Clindamycin p.o. therapiert werden. Hintergrund dieser Empfehlung ist

a. eine hoher Grad der pulmonalen Entzündung bei. Staph.aureus-Infektion,

b. eine signifikant schlechtere Lungenfunktion im Alter von 5 Jahren bei Nachweis von Staph.-aureus während der ersten zwei Lebensjahre,

c. strukturelle Lungenveränderungen infolge der Infektion,

d. schlechterer Ernährungszustand.

Wenn eine Koinfektion mit P. aeruginosa und Staph.aureus vorliegt und eine antibiotische Therapie gegen P. aeruginosa beabsichtigt ist, wird empfohlen, den Staph.aureus antibiotisch mit abzudecken.

Unklarheit herrscht über die Indikation einer prophylaktischen Therapie. Die Evidenz für oder gegen eine Eradikationstherapie ist nicht ausreichend. Die europäische Leitlinie für Kinder in den ersten 2 Lebensjahren sieht die Vorteile einer Staphylokkenprophylaxe im 1. Lebensjahr in einer geringeren Isolationsrate. Sie kritisiert aber, dass die langfris- 
tigen Effekte (wie höhere Kolonisation mit P. aeruginosa) unklar sind.

\section{Anaerobe Bakterien}

Anaerobe Bakterien (Prevotella, Veillonella, Propionibacterium, Actinomyces, Staphylococcus saccharolyticus, Peptostreptococcus, Clostridium, Streptococus milleri und Actinomyces) können bei erwachsenen CF-Patienten $(64 \%)$ in hoher Zahl im Sputum isoliert werden. Die Besiedlung mit $\mathrm{P}$. aeruginosa steigert die Wahrscheinlichkeit des Nachweises von anaeroben Bakterien im Sputum. In der BAL von Kindern fanden sich ähnliche anaerobe Bakterien. Alle oben genannten Bakterien sind in der Regel sensibel auf Meronem. Sofern Anaerobier neben den primären Erregern (z. B. P. aeruginosa) signifikant zur Infektion und Entzündung beitragen, sollten sie antibiotisch mitbehandelt werden.

\section{Achromobacter xylooxidans}

Die Prävalenz wird mit 3-30 \% angegeben. In Deutschland findet sich der Keim mindestens 1-mal jährlich bei 3,3 \% der Kinder und 6,8 \% der Erwachsenen. Eine chronische Besiedlung wird bei 1,3\% der Kinder und 5,4\% der Erwachsenen nachgewiesen. Etwa 11-30 \% der initial Kolonisierten, werden chronisch infiziert. Die Risikofaktoren sind nicht eindeutig. Diskutiert werden zunehmendes Alter, Schwere der Erkrankung und chronische P.-aeruginosa-Infektion. Unklar ist auch welchen Einfluss Achrombacter-Infektionen auf den Verlauf haben. Kleine Studien zeigten schlechtere Lungenfunktionen und radiologisch schwerere Befunde. Oft findet sich eine Antibiotikaresistenz, multiresistente Stämme (MDR) sind häufig. In-vitro-Aktivität findet sich für Imi-/ Meropenem, Piperacillin/Taczobactam und Minocyclin. Eine Therapie nach Antibiogramm ist empfohlen.

\section{Virale Infektionen}

Virale Erreger konnten in bis zu $60 \%$ bei pulmonalen Exazerbationen bei Kindern isoliert werden. Das Spektrum der Erreger entspricht dem von Gesunden: Rhinovirus, RSV, Influenza, Parainfluenza, Adenovirus, Bocavirus, Coronavirus, Rhinovirus, Picornavirus und humanes Metapneumovirus. Inzwischen erfolgt der Erregernachweis mittels PCR-gestütztem Nachweis aus den Atemwegssekreten. Die bisher gültige These gleicher Prävalenz viraler Besiedlungen wie bei Gesunden wurde infrage gestellt: In einer longitudinalen Studie (CF-Kinder mit gesunden Kontrollen gematcht) wurde gezeigt, dass CF-Kinder bei gleicher RhinovirusExposition eher infiziert werden und das Virus länger repliziert wird. Ob virale Infektionen die Inzidenz bakterieller Infektionen steigern, wird widersprüchlich diskutiert.

Bei Säuglingen und Kleinkindern mit CF und viralen Infekten fand sich ein erhöhtes Hospitalisationsrisiko wie eine verlängerte Zeit, bis der Verlust an Lungenfunktion wieder eingeholt werden konnte.
Therapieoptionen Für eine prophylaktische Gabe von RSV-Immunglobulin gibt es keine ausreichende Evidenz. Die Empfehlung zur jährlichen intramuskulären InfluenzaImpfung des Robert-Koch-Institutes besteht. Aufgrund schlechterer Wirksamkeit wurde die Empfehlung zur nasalen Applikation zurückgezogen.

\section{Pilze}

Die Prävalenz von Pilzen und ihre Bedeutunng für die pulmonale Infektion bei CF ist vormals unterschätzt worden. Die verbesserten Nachweismethoden (molekulare Techniken und Genotyping) haben dazu geführt, die nicht erkannten Pilzinfektionen zu diagnostizieren. Endogene Faktoren bei CF, wie gestörte mukoziliäre Clearance und lokale immunologische Defizite, spielen eine Rolle. Der vermehrte Einsatz inhalativer Antibiotika bei zunehmendem Alter bzw. eine steigende Menge an kumulativ verabreichten inhalativen Antibiotika schafft auf den Atemwegen ein pilzfreundliches Milieu. Klinisch relevant sind vor allem: Aspergillus fumigatus, Candida albicans und Scedosporium species.

Aspergillus fumigatus Molekulargenetische Untersuchungsmethoden haben gezeigt, dass die Besiedlung mit Aspergillus fumigatus bei Kindern mit $\mathrm{CF}$ unterschätzt wurde. Im Median findet sich bereits ein serologischer Nachweis im Alter von 5,5 Jahren. Im Sputum wird Asp. fumigatus im Mittel im Alter von 12,3 Jahren nachgewiesen.

Asp.-fumigatus-Sporen (Conidia) können aufgrund ihrer geringen Größe $(2-4 \mu \mathrm{m})$ in die terminalen Alveolen vordringen. Pathophysiologisch profitiert Asp. fumigatus von einer gestörten mukoziliären Clearance. Klinisch sind 4 unterschiedliche Phänotypen beschrieben.

Aspergillus-Besiedlung Bei einer reinen Kolonisierung der Atemwege findet sich laborchemisch kein Nachweis auf eine allergische Reaktion (IgE negativ). Es konnte gezeigt werden, dass eine Kolonisierung mit einer gesteigerter Entzündung in der BAL, einer Steigerung hospitalisationspflichtiger Exazerbationen und vermehrten Verlust an Lungenfunktion einhergeht. Daher ist eine antimykotische Therapie zu diskutieren. Eine placebokontrollierte doppelblinde Studie mit Itraconazol führte zu keinem klinischen Benefit. Ob Patienten von einer antimykotischen Therapie klinisch profitieren, bleibt bisher offen.

Aspergillus-Bronchitis Bei dieser klinischen Variante findet sich eine hohe Aspergilluslast im Sputum ohne Hypersensitivitätsnachweis und Zeichen der bakteriellen Exazerbation: produktiver Husten, zunehmende Sputumviskosität, Atemnot und Hämoptysen. Diese Patienten profitieren von einer antimykotischen Therapie. 
Allergisch-bronchopulmonale Aspergillose (ABPA) Häufigstes klinisches Problem ist die allergisch-bronchopulmonale Aspergillose. In Deutschland findet sich bei Kindern eine Prävalenz von 3,9\%, bei Erwachsenen von 8,3 \%. Ein Asp.fumigatus-Nachweis korreliert aber nicht mit einer ABPA. Differenzialdiagnostische Probleme ergeben sich zwischen infektiöser Exazerbation (entsprechend der Fuchs-Kriterien, siehe oben) und den ABPA-Kriterien der CF-FoundationKonsensuskonferenz:

1. Akute oder subakute Verschlechterung bzw. Symptome (Husten, Giemen, Belastungsintoleranz, anstrengungsinduzierte Bronchialobstruktion, Verschlechterung der Lungenfunktion, gesteigerte Sputummenge), welche nicht

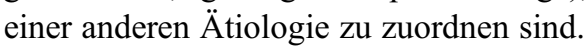

2. Gesamt-IgE >1000 IU/ml (sofern der Patient nicht mit systemischen Steroiden behandelt wird).

3. Positiver Pricktest auf Asp. fumigatus (Papel $>3 \mathrm{~mm}$ ) oder In-vitro-Nachweis von Serum-IgE-Antikörpern gegen Asp. fumigatus.

4. Präzipitierende Antikörper gegen Asp. fumigatus oder IgG-Antikörper gegen Asp. fumigatus.

5. Neue oder kürzlich zurückliegende Auffälligkeiten im Röntgenthorax (Infiltrate oder Schleimpfropfen) oder CT-Thorax (Bronchiektasen, Blütenzweige (Tree in bud) etc.), welche auf Antibiotika oder Physiotherapie keine Besserung zeigen.

Ein Nachweis von Asp. fumigatus im Sputum ist jedoch nicht obligat.

Die Standardtherapie der ABPA besteht in systemischen Steroide (Prednisolon 1-2 mg/kg KG/Tag, maximal $60 \mathrm{mg}$ / Tag). Bei klinischem Ansprechen werden die Steroide langsam über 3 Monate ausgeschlichen. Diese führen zur Reduktion der entzündlichen und immunologischen Aktivität, haben aber keinen Effekt auf die Antigenbelastung. Eine Reduktion der Pilzlast in den Atemwegen kann die antigene Stimulation und die Entzündung reduzieren. Mittel der 1. Wahl ist Itraconazol. Aufgrund der besseren Bioverfügbarkeit wird die orale Gabe vorgezogen. Spiegelkontrollen (Talspiegel) sollten nach einer Woche erfolgen. Indikationen zur Itraconazolgabe sind

- geringes Ansprechen auf Steroide,

- Rückfall bei Steroidreduktion,

- klinisch manifeste Nebenwirkungen der Steroide,

- Steroidabhängigkeit.

Aufgrund der zunehmenden Resistenz gegen Itraconazol stehen als Alternativpräparate Voriconazol und Posaconazol zur Verfügung. Die Antimykotikagabe erfolgt zusätzlich zu den Steroiden.
Eine Alternative $\mathrm{zu}$ den nebenwirkungsreichen Steroiden ist der Anti-IgE-Antikörper Omalizumab.

Aspergillussensibilisierung Im Gegensatz zur ABPA finden sich serologisch hier nur IgE-Antikörper, aber keine IgG-Antikörper (sowie keine Galaktomannan-Antikörper im Sputum). Klinisch kann dies aber ebenfalls mit einer Verschlechterung der Lungenfunktion einhergehen.

Aspergillome können selten in vorexistierenden pulmonalen Bronchiektasen auftreten. Asp. fumigatus lässt sich in chronisch verlegten Nasennebenhöhlen finden. Ein wiederholter Nachweis von einem Aspergillus-Antigen sollte nach entsprechender Empfindlichkeitsprüfung antimykotisch behandelt werden. Bei transplantierten CF-Patienten kann es zu einer invasiven pulmonalen Aspergillose kommen.

Candida albicans In einer prospektiven longitudinalen Studie fand sich eine Besiedlung bei 49,4 \% der Patienten. Dieses geht mit gesteigerten Hospitalisationen bei Exazerbationen und einem langfristigen Abfall im BMI und FEV1 einher. Die klinische Bedeutung bleibt offen, für eine Behandlungsindikation gibt es keine Evidenz.

Scedosporium species Aufgrund taxonomischer Änderungen unterscheidet man inzwischen den Scedosporium apiospermium Komplex (S. apiosporium sensu stricto, S. boydii [vormals Pseudoallescheria boydii], S. aurantiacum, S. minutispora und S. dehoggii). Wegen genetischer Unterschiede wird S. prolificans nun den Lomentuspora zugeordnet. Er heißt jetzt Lomentuspora prolificans. In Deutschland liegt die Prävalenz zwischen 3,1 und 5,3\%. Bei nichttransplantierten Patienten findet sich eine leichte Zunahme respiratorischer Symptome (Sputummenge, Husten und Dyspnoe). Kritisch sind diese Pilze unter Immunsuppression wie nach Lungentransplantation. Aufgrund der negativen Auswirkungen wird diese Besiedlung auch als Kontraindikation für eine Lungentransplantation diskutiert. Daher sollte eine Eradikation bei erster Isolation versucht werden. Mittel der Wahl ist Voriconazol (evtl. auch in Kombination mit anderen Antimykotika wie Amphotericin B, Caspfungin).

Exophalia dermatididis Exophalia dermatididis findet sich mit einer Prävalenz von 1 bis zu $19 \%$ bei CF. Pulmonale Manifestationen sind beschrieben. Der Nachweis kann sich schwierig gestalten, Spezialnährböden und eine lange Bebrütungsdauer können nötig sein.

\section{Physiotherapie}

Physiotherapeutische Maßnahmen dienen der Sekretmobilisation und Unterstützung der Expektoration und sind einschließlich Sport- und Rehabilitationstherapie im Detail in den entsprechenden Beiträgen dargestellt. 


\section{Inhalationstherapie}

\section{Beta2-Sympathomimetika}

Patienten mit bronchialer Hyperreagibilität profitieren von der Inhalation mit $\beta 2$-Sympathomimetika. Eine präventive Wirkung gegen Bronchospasmus bei Therapie mit inhalativen Antibiotika ist belegt. Für den chronischen Gebrauch findet sich keine Evidenz für oder gegen eine solche Empfehlung für Kinder im Vorschulalter (2-5 Jahre). Vergleichende Studien haben eine Überlegenheit des langwirkenden Salmeterol gegenüber dem kurzwirksamen Albuterol gezeigt. Als Vorteil der langwirksamen ß2-Sympathomimetika wurde die geringere Einnahmehäufigkeit (1-mal/die) im Vergleich zu den kürzer wirksamen ß2-Sympathomimetika (3- bis 4-mal/die) gewertet. In Bezug auf die Problematik der Einnahme langwirkender ß2-Sympathomimetika ohne Therapie mit inhalativen Steroiden (ICS) sei an die entsprechende Literatur bei Asthma verwiesen (bzw. gegebenenfalls die Indikation für ICS zu prüfen).

Die deutsche Leitlinie empfiehlt den Einsatz von $\beta 2$-Sympathomimetika bei chronischer Pseudomonas-Infektion, insbesondere zur vorbeugenden antiobstruktiven Behandlung im Rahmen von inhalativen Therapien (z. B. inhalative Antibiotika).

Die neuen langwirkenden B2-Sympathomimetika (Indacaterol, Olodanterol und Adediterol) sind nur für COPD zugelassen. Vilanterol ist bei Asthma ab dem 12. Lebensjahr zugelassen. Studien bei CF liegen bisher nicht vor.

\section{Anticholinergika}

Bei chronischer Pseudomonas-Infektion und Unverträglichkeit von ß2-Sympathomimetika sollte die Gabe von Anticholinergika zur vorbeugenden antiobstruktiven Behandlung im Rahmen von inhalativen Therapien (z. B. inhalative Antibiotika) erwogen werden.

Die neuen Anticholinergika (Glycopyronium, Aclidinium, Umeclidinium) sind nur für COPD zu gelassen. Studien bei $\mathrm{CF}$ liegen bisher nicht vor.

\section{Dornase alfa}

Im Rahmen des Unterganges von Neutrophilen werden große Mengen Desoxyribonukleinsäure (DNA) freigesetzt. Dies führt zu viskösem Sputum und zu Schleimpfropfen. Dornase alfa reduziert die Viskosität. In Studien konnte eine signifikante Verbesserung der Lungenfunktion und eine nichtsignifikante Reduktion von pulmonalen Exazerbationen gezeigt werden. Der LCI verbesserte sich nach 1 Monat. An Nebenwirkungen sind Hautausschläge und Veränderungen der Stimme beschrieben. Für eine Überlegenheit von Dornase alfa $\mathrm{zu}$ anderen hyperosmolaren Substanzen (hypertone Kochsalzlösung, Mannitol) in vergleichenden Untersuchungen gibt es keine ausreichende Evidenz.
Die Inhalationstherapie mit Dornase alfa (1-mal 2,5 mg/ die) wird in den amerikanischen Richtlinien bei Kindern $>6$ Jahren auch bei milder Erkrankung oder asymptomatischen Verlauf empfohlen. Bei chronischer Pseudomonas-Infektion soll nach deutscher Leitlinie die Umstellung bzw. Ergänzung mit Dornase alfa erwogen werden.

\section{Hypertone Kochsalzlösung}

Die hypertone Kochsalzlösung steigert (6-7 \%) die Hydratation der „airway surface liquid“ (ASL) und die mukoziliäre Clearance. Es konnte gezeigt werden, dass eine Inhalation von 7-prozentiger Kochsalzlösung zu einer geringen FEV1Verbesserung nach 4 Wochen führte, dieses war aber nach 48 Wochen Therapie nicht mehr nachweisbar. Auch wenn hypertone Kochsalzlösung im Gegensatz zu Dornase alfa keine dauerhafte Verbesserung der Lungenfunktion bewirkt, führt sie aber zu einer Verbesserung der Lebensqualität und zu einer Reduktion pulmonaler Exazerbationen. Sofern eine Kochsalzlösung in einer höheren Konzentration nicht vertragen wird, kann auch die Inhalation von 3-prozentiger Kochsalzlösung versucht werden.

\section{Mannitol}

Mannitol-Trockenpulver (2-mal $400 \mathrm{mg} / \mathrm{die}$ ) führt zu einer signifikanten Verbesserung der Lungenfunktion (FEV1). Offen ist aber die Frage, welche Patienten von Mannitol als Monotherapie oder in Kombination mit Dornase alfa profitieren und wie lange dieser Effekt anhält. Daher müssen noch Studien folgen, bevor es als Mukolytikum allgemein empfohlen werden kann.

\section{Antiinflammatorische Therapie Ibuprofen}

Eine hochdosierte Gabe (25 mg/kg KG 2-mal/Tag) führt zu einem signifikant geringeren Abfall der FEV1, besonders bei jüngeren Patienten im Alter von 5-13 Jahren. Retrospektive Analysen konnten jedoch zeigen, dass viele Patienten aufgrund gastrointestinaler Beschwerden die dauerhafte Einnahme ablehnten.

Nach den amerikanischen Therapieleitlinien findet sich für Patienten im Alter von 6-17 Jahren eine Empfehlung aufgrund einer moderaten Verbesserung. Für Erwachsene reicht die Datenlage für eine Empfehlung nicht aus. Die Leitlinie für Vorschulkinder (2-5 Jahre) kommt auch zu dem Schluss, für eine Therapieempfehlung reiche die Evidenz in dieser Altersstufe nicht aus. Nach der deutschen Leitlinie zur Therapie der chronischen P.-aeruginosaInfektion kann bei Progression der Lungenerkrankung je nach Symptomen und Alter eine Hochdosis-Therapie erwogen werden.

Aufgrund der renalen Nebenwirkungen ist es wichtig entsprechende Blutspiegelbestimmungen durchzuführen. 


\section{Orale Steroide}

Obwohl sich ein positiver Effekt auf die Lungenfunktion findet, wird für Vorschulkinder (2-5 Jahre) und Schulkinder (6-18 Jahre) ohne Asthma oder aufgrund der Nebenwirkungen von einer Dauertherapie abgeraten. Die deutsche Leitlinie zur Therapie der chronischen P.-aeruginosa-Infektion spricht sich gegen eine systemische Langzeittherapie mit Kortison aus.

\section{Inhalative Steroide}

Eine Empfehlung Kinder ohne Asthma oder ABPA mit inhalativen Steroiden zu behandeln besteht nicht. Daher sollte bei rezidivierenden Obstruktionen eine entsprechende Abklärung auf Asthma (signifikanter Broncholysetest, Hyperreagibilitätstestung) stattfinden. Die deutsche Leitlinie zur Therapie der chronischen P.-aeruginosa-Infektion spricht sich mangels Evidenz gegen den supportiven Einsatz von inhalativen Steroiden aus.

\section{Leukotrienrezeptorantagonisten}

Auch wenn die wenig verfügbaren Studien z. T. eine Verbesserung der Lungenfunktion zeigen, beurteilen die amerikanischen Richtlinien den Evidenzgrad nicht als ausreichend, um eine positive Empfehlung auszusprechen.

\section{N-Acetylcystein}

Für einen therapeutischen Effekt gibt es keine Evidenz. Die deutsche Leitlinie für chronische P.-aeruginosa-Infektion spricht sich gegen den supportiven Einsatz von $\mathrm{N}$-Acetylcystein aus.

\section{Azithromycin \\ Eine Azithromycindauertherapie $(10 \mathrm{mg} / \mathrm{kg} \mathrm{KG} / \mathrm{Tag}$; maxi- mal $500 \mathrm{mg} / \mathrm{Tag}$ ) jeweils an 3 Tagen (Mo/Mi/Fr) der Woche wird in den amerikanischen Leitlinien bei chronischer Besiedlung mit P. aeruginosa ab dem Schulalter empfohlen. Die Vorteile einer Azithromycindauertherapie liegen in der Verbesserung der Lungenfunktion und der Reduktion pul- monaler Exazerbationen. Ferner zählt ein signifikant niedri- gerer Bedarf an oralen Antibiotika und eine Gewichtszu- nahme zu den erwünschten Effekten. Laut deutscher Leitlinie soll diese Therapie nur erwogen werden. Hinter- grund der zurückhaltenderen Bewertung sind Studien, die eine erhöhte Prävalenz von Infektionen mit nichttuberkulö- sen Mykobakterien zeigen. Es wird empfohlen, Patienten auf die Kolonisierung mit nichttuberkulösen Mykobakterien vor Beginn einer entsprechenden Dauertherapie zu untersu- chen. Unter Azithromycindauertherapie sollte dieser Befund alle 6-12 Monate kontrolliert werden. Auch fand sich in Studien eine verminderte Wirksamkeit von inhalativem Tobramycin bei gleichzeitiger Gabe.}

\section{Neue (kausale) Therapien CFTR-Modulatoren}

Diese Medikamente modulieren das CFTR-Protein (cystic fibrosis transmembrane regulator protein) und stellen die Ionentransportfunktion wieder her.

CFTR-Potenziatoren Die epitheliale Sekretion von Chlorid und Bikarbonat wird von CFTR-Potenziatoren erhöht durch Verlängerung der Kanalöffnungszeiten. Bei den meisten Klasse-III- und Klasse-IV-Mutationen verbessert Ivacaftor so den CFTR-vermittelten Chloridtransport und stellt die mukoziliäre Funktion wieder her. In einer Reihe von klinischen Studien konnte eine hohe Wirksamkeit bei Klasse-III-Mutationen wie Gly551Asp (G551D) und 8 weiteren Typ-III-Gating-Mutationen (Gly551Ser, Gly178Arg, Gly1244Glu, Gly1349Asp, Ser549Asn, Ser549Arg, Ser1251Asn, Ser1255Pro) gezeigt werden:

a. $10 \%$ Verbesserung der FEV1,

b. $50 \%$ niedrigerer Chloridwert im Schweißtest,

c. verbesserte Lebensqualität,

d. Reduktion pulmonaler Exazerbationen,

e. Verbesserung des Ernährungszustandes (BMI).

Für Klasse-IV-Mutationen (Arg117His) fand sich keine signifikante Verbesserung der Lungenfunktion, aber eine Reduktion des Chloridwertes im Schweiß um $25 \%$. Unerwünschte Nebenwirkungen sind passagere Leberwerterhöhungen (Leberwertekontrollen zu Beginn, alle 3 Monate im 1. Jahr, dann jährlich). Im Tierversuch wurden Linsentrübungen beobachtet, augenärztliche Untersuchungen sind vor Therapiestart und im Verlauf empfohlen. Ivacaftor ist Substrat von CYP3A4 und CYP3A5, insofern sind Wechselwirkungen möglich.

Ivacaftor ist als Granulat ab dem 2. Lebensjahr in Deutschland zugelassen für folgende Mutationen: G551D-, G1244E-, G1349D-, G178R-, G551S-, S1251N-, S1255P-, S549N-, S549R-G. In Österreich und der Schweiz besteht ebenfalls für oben genannte Mutationen die gleiche Zulassung. Die Zulassung für die Mutation R117H besteht ab dem 18. Lebensjahr in Deutschland und der Schweiz.

CFTR-Korrektoren Die zu den CFTR-Korrektoren zählenden Substanzen werden im Folgenden näher beschrieben.

Lumacaftor (Vertex 809) Für die häufigste Mutation F508del findet sich eine fehlerhafte Faltung im endoplasmatischen Retikulum was auch zum vorzeitigen Abbau des Proteins und einer zu geringen Expression an der Zelloberfläche führt. Der Korrektor Lumacaftor korrigiert partiell diese Faltungsdefizite. Er führt zur Stabilisierung des Proteins. Allerdings führt dieses zu einer klinisch nicht ausreichen- 
den Aktivität von F508del-CFTR. Klinisch erfolgreich ist die Kombination mit dem Potenziator Ivacaftor bei homozygoten F508del. In 2 randomisierten placebokontrollierten Studien (TRAFFIC und TRANSPORT) fand sich über 24 Wochen:

a. signifikante Verbesserung der Lungenfunktion (absolute FEV1\%pred: $+2,8 \%$ ),

b. des BMI $\left(+0,24 \mathrm{~kg} / \mathrm{m}^{2}\right)$ und

c. Reduktion der Infektexazerbationen ( $-39 \%)$.

Unerwünschte Nebenwirkungen sind passageres pulmonales Engegefühl und/oder erhöhte Leberwerte. Wechselwirkungen bestehen aufgrund der CYP3A-Induktion (unter anderem Wirkungsabschwächung hormonaler Kontrazeptiva).

Das Kombinationspräparat Lumacaftor/Ivacaftor (Handelsname: Orkambi) ist für Patienten (delta F508 homozygot) ab dem 2. Lebensjahr in Deutschland und Österreich zuge- lassen. In der Schweiz gibt es eine entsprechende Zulassung ab dem 6. Lebensjahr.

Kritisch an der Lumacaftor/Ivacaftor-Therapie wird der im Vergleich zu anderen Medikationen geringe Zuwachs an Lungenfunktion diskutiert. Eine bedingte Empfehlung gibt es für diese Patientengruppe mit einer FEV1>90\% und für Kinder von 6-11 Jahren. Vor dem Hintergrund, dass nur ein Fünftel der Patienten in der Wainwright-Studie eine Verbesserung der FEV1 absolut um $8 \%$ hat, hat die Medizinische Hochschule Hannover einen Algorithmus entwickelt (Abb. 5).

Aufgrund der höheren Sensitivität der multiple breath washout (MBW) wird inzwischen auch diese Messgröße zur Beurteilung der Lungenfunktion von CFTR-Modulatoren in Studien herangezogen.

Das Problem von Lumacaftor ist eine Induktion von CYP3A4-Enzymen, was sich auch negativ auf die Bioverfügbarkeit von Ivacaftor auswirkt.

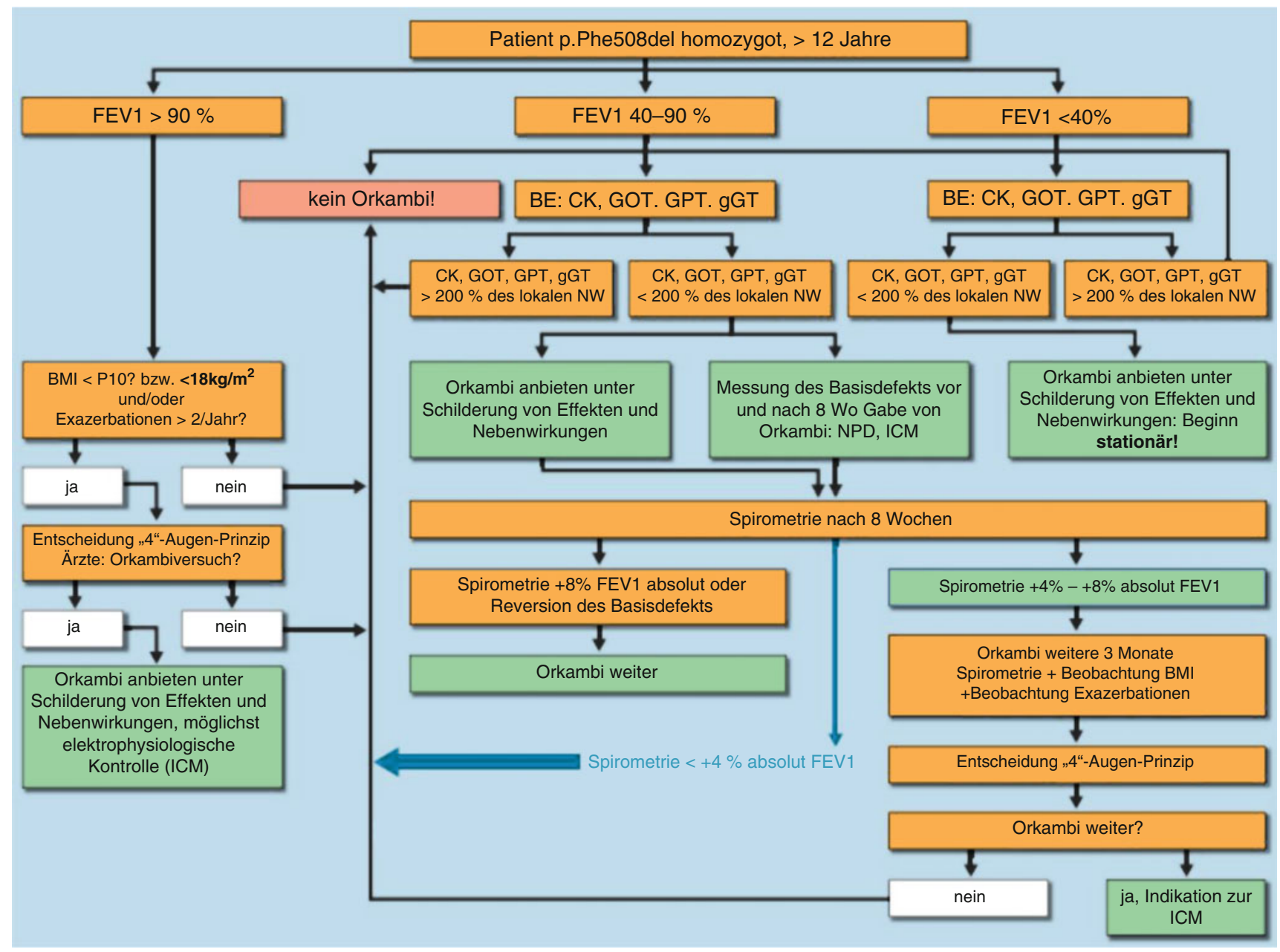

Abb. 5 Konsentierter Entscheidungsbaum des CF-Teams an der Medizinischen Hochschule Hannover zur Verordnung von Orkambi. Die Indikation zur Gabe von Orkambi wird bei p.Phe508del homozygoten CF-Patienten mit einer FEV1 von 40-90 \% des Solls evlauiert, wenn alle Serumwerte für die Kreatinkinase $(C K)$ und die Leberenzyme (GOT,
$G P T$ und $\gamma-G T)$ um weniger als das 2-Fache der oberen Normgrenze erhöht sind (NPD nasale Potenzialdifferenzmessung, ICM intestinale Kurzschlussstrommessung; mit freundl. Genehmigung von Tümmler et al. 2016) 
Tezacaftor (Vertex 661) Tezacaftor (Vertex 661), ein weiterer Korrektor, induziert die CYP3A4-Enzyme aber nicht. Diese Interaktionen spielen für viele CF-Therapeutika (z. B. Antimykotika) eine Rolle. Unter Tezacaftor gibt es daher weniger Wechselwirkungen als unter Lumacaftor. In Studien bei Delta-F508-Homozygoten (EVOLVE) fand sich ein akzeptables Nebenwirkungsprofil für Tezacaftor in Kombination mit Ivacaftor. Darüber hinaus fanden sich eine verbesserte Lungenfunktion ( $4 \%$ besser als Placebo für FEV1) und $35 \%$ weniger pulmonale Exzerbationen nach 24 Wochen.

Eine zweite Studie (EXPAND) untersuchte Patienten, die eine Mutation aufweisen, die zu einer CFTR-Restfunktion und einer F508del-Mutation führt, mit einer Kombination Tezacaftor/Ivacaftor. Es kam zu einer mittleren absoluten Verbesserung der Lungenfunktion (FEV1) von 6,8 Prozentpunkten gegenüber Placebo (gemittelt nach 8 Wochen). Unter dem Handelsnamen Symkevi ist die Kombination Tezacaftor/ Ivacaftor in deutschland und Österreich (Schweizer Zulassung folgt) für Patienten ab dem 12 Lebensjahr zugelassen für Delta-F508-Homozygote und jene, welche eine Mutation aufweisen, die zu einer CFTR-Restfunktion und einer DeltaF508-Mutation führt.

Studien (Phase 2) mit einer Kombination von Tezacaftor und Ivacaftor und einem 3. Korrektor (Vertex 659 oder Vertex 445) führten bei Delta-F508-Heterozygoten und einer weiteren Minormutation (nach 28 Tagen) zu einem signifikanten Anstieg der FEV1 (13,3 \%/13,8 \%) wie eine Minderung des Choridgehaltes im Schweißtest $(-43,7 /-39,1 \mathrm{mmol} / \mathrm{l})$ bei guter Verträglichkeit. Weitere Phase-2-Korrektorstudien (Vertex 440, Vertex 152) in Kombination mit Tezacaftor und Ivacaftor werden bei Delta-F508-Heterozygoten und einer weiteren Minormutation durchgeführt.

Amplifier Amplifier steigern die Menge an CFTR-Protein in der Zelle. So steht mehr CFTR-Protein für andere Therapeutika zur Verfügung wie Ivacaftor und Lumacaftor. In einer Phase-1-Studie wird der Amplifier PTI-428 untersucht.

\section{Gentherapie}

Eine randomisierte doppelblinde, placebokontrollierte Phase2b-Studie untersuchte eine inhalative Gabe von einer PlasmidDNA, welche das CFTR kodiert. Als nicht viraler Vektor diente ein Liposomkomplex, der monatlich über $1 \mathrm{Jahr}$ inhaliert wurde: 116 CF-Patienten ( $\geq 12$ Jahre, FEV1,50-90 \%) mit jeglicher CFTR-Mutation nahmen an der Studie teil. Es kam zu einem signifikanten, aber relativ geringem FEV1-Anstieg von 3,7 \%, aber zu keiner Verbesserung der Lebensqualität. Insofern ist die Evidenz einer Wirksamkeit zu gering, um diese Therapie bereits als Routinetherapie zu etablieren. Therapien mit viralen Vektoren zeigten keine Wirksamkeit.

\subsection{Komplikationen}

\section{Hämoptysen}

Etwa 9,1 \% der CF-Patienten leiden an Hämoptysen in einem 5-Jahreszeitraum. Eine massive Hämptoe erleiden 4,1 \% der CF-Patienten in ihrem Leben, die durchschnittliche jährliche Inzidenz liegt bei $0,87 \%$ oder 1 in 115 Patienten/Jahr. Im Jahr 2016 finden sich im deutschen Register bei 1,1\% der Kinder und 9,3\% der Erwachsenen Hämoptysen. Davon waren $4,2 / 5,1 \%$ schwerwiegend.

Man unterscheidet zwischen geringer $(<5 \mathrm{ml})$, milder bis moderater $(5-240 \mathrm{ml})$ und massiver Hämptyse $(>240 \mathrm{ml})$. Bei geringer Hämoptyse wird noch keine Hospitalisierung empfohlen. Wenn sich keine Zeichen der pulmonalen Exazerbation zeigen, ist eine antibiotische Therapie nur bedingt notwendig. Patienten mit massiven Hämoptysen müssen stationär behandelt werden.

Bei milder Blutung sollte, wenn der Patient unter der Therapie mit nichtsteroidalen Antiphlogistika steht, diese gestoppt werden (wegen des Blutungsrisikos der NSAID). Eine Embolisation der Bronchialarterien sollte bei instabilen Patienten mit massiver Hämoptoe erfolgen. Für eine Bronchoskopie vor der Intervention gibt es keine Empfehlung. Klare Empfehlungen, ob alle abnormen Gefäße embolisiert werden sollten oder nur jene, die verdächtig sind, existieren nicht. Gefahren der Embolisation liegen in der ungewollten Embolisation einer Spinalarterie. Bei Patienten mit geringer Blutung sollte BiPAP (biphasic positive airway pressure) weitergeführt werden, bei massiver Blutung ist eine Pause empfohlen. Eine Lungenresektion bei massiver Hämptyse bleibt die Ultima Ratio.

Physiotherapie und Atemgymnastik sollte bei geringer Blutung weitergeführt werden, eine Unterbrechung wird bei massiver Hämoptyse empfohlen. Die Inhalationstherapie sollte bei leichter Hämptyse weitergeführt werden, bei massiver Hämoptoe sollte die Inhalation von hypertoner Kochsalzlösung unterbrochen werden.

\section{Pneumothorax}

Im Jahr 2016 findet sich im deutschen Register eine Inzidenz bei $0,5 \%$ der Kinder und 1,4 \% der Erwachsenen. Davon waren 70/48,6 \% drainagepflichtig. Die Größe des Pneumothorax wird als die Distanz zwischen Apex und Kuppel der Lunge bemessen. Es werden kleine $(\leq 3 \mathrm{~cm})$ und große $(>3 \mathrm{~cm})$ große Pneumothoraces unterschieden. Die stationäre Behandlung wird bei großen Pneumothoraces empfohlen. Bei einem kleinen Pneumothorax kann der Patient, sofern er klinisch stabil ist, ambulant geführt werden. Die Indikation für eine Drainage besteht bei einem großen und bei einem kleinen Pneumothorax, sofern der Patient klinisch instabil ist. Eine chirurgische Pleurodese wird bei rezidivierenden groBen Pneumothoraces empfohlen; BiPaP sollte unterbochen werden. Bis zu 2 Wochen nach Rückbildung des Pneumo- 
thorax sollte der Patient nicht fliegen oder tauchen, keine Spirometrie durchführen und nicht Lasten von mehr als $4,5 \mathrm{~kg}$ heben. Atemgymnastik wie PEP und intrapulmonale Perkussionsventilation sollten beim großen Pneumothorax in den meisten Fällen unterbrochen werden. Es besteht keine Indikation die Inhalationstherapie zu unterbrechen.

\section{Lungentransplantation Epidemiologie}

Die erste Lungentransplantation bei CF wurde 1983 durchgeführt. In Deutschland wurden im Jahr 2016 bei CF 70 Lungentransplantationen durchgeführt. Der Median der Überlebensdauer nach Lungentransplantation liegt bei 7,5 Jahren. Wird das erste postoperative Jahr überlebt, liegt der Median des Überlebens bei 10,4 Jahren.

\section{Vorbereitung}

Ein Prätransplant-Assessment ist indiziert, bei FEV1 $<30 \%$ des Sollwertes und/oder schnellem therapieresistenten Abfall der FEV1, Unterernährung und Diabetes mellitus, weiblichem Geschlecht, häufigen Exazerbationen und/oder steigendem Bedarf an i.v.-Antibiotikatherapie, rezividivierenden deutlichen Hämoptysen (durch Embolisation nicht steuerbar), rezidivierenden Pneumothoraces oder intensivmedizinischer Behandlung. Weitere Kriterien sind (1) respiratorische Partialinsuffizienz (sauerstoffpflichtig), (2) Hyperkapnie und (3) pulmonaler Hypertonus.

Eine Listung sollte bei verminderter Lebenserwartung erfolgen. Diese sollte aber über der Wartezeit (auf der Liste) liegen. Während der Wartezeit sollte der Patient physisch aktiv sein, um die Muskelmasse und die Knochendichte zu erhalten. Impfungen sollten komplettiert werden. Das soziale Netz des Patienten sollten mittels professioneller Unterstützung für die peri- und postoperative Phase gestärkt werden. Auch sollte der Patient emotional auf diese Phase vorbereitet werden.

Zum Prätransplant-Assessment gehören eine Reihe von Funktionsuntersuchungen (unter anderem HLA-Labor, Lungenfunktion, Thorax-CT, BGA, Sputumkultur, EKG, Echo, Ernährungszustand, US-Abdomen, Knochendichtemessung, gynäkologisches/urologisches Konsil, psychologische Testung, Zahnstatus, augenärztliches und dermatologisches Konsil).

Kontraindikationen sind maligne Erkrankungen in den letzten 2 Jahren, schwere extrapulmonale Erkrankungen (schwere Nieren- oder Leberinsuffizienz, koronare Herzerkrankung). Aktive Infektionen wie aktive unbehandelte Tuberkulose, chronische Hepatitis B sind absolute Kontraindikationen, ebenso eine schwere Osteoporose mit Frakturen, dokumentierte mangelnde Therapieadhärenz, unbehandelbare Psychosen und Suchterkrankungen (innerhalb der letzten 6 Monate Nikotin-, Alkohol-, Drogen- und Medikamentenabusus).
Eine endotracheale Intubation und mechanische Beatmung gilt nicht mehr als Kontraindikation. Inzwischen wird mittels invasiver Beatmung und extrakorporaler Membranoxygenierung (ECMO) die kritische Phase vor Transplantation überbrückt. Die Einstellung von Erkrankungen wie Diabetes mellitus, gastroösophagealem Reflux und Osteoporose muss vor Transplantation optimiert werden.

Die Kolonisierung mit multi- oder panresistenten P. aeruginosa und gramnegativen Bakterien, wie S. maltophilia oder Achromobacter sowie MRSA, sind kein Grund eine Transplantation abzulehnen. Im Gegensatz dazu kann eine Infektion mit Burkholderia cepacia complex (Bcc) zum Cepacia-Syndrom führen. Diese septische Verlaufsform bei B. cenocepacia, B. multivorans und B. dolosa geht mit höheren Mortalitätsraten nach Transplantation bei CF einher. Viele Zentren lehnen daher in dieser Konstellation die Transplantation ab. Allerdings sollte eine individuelle Abwägung erfolgen.

Nichttuberkulöse Mykobakterien (NTM) können sehr problematisch nach der Transplantation werden. Ihr Nachweis gilt aber nicht als absolute Kontraindikation.

Ein ausgewogener Ernährungstatus sollte schon lange vor dem Transplantationszeitpunkt angestrebt werden.

\section{Perioperative Phase}

Folgende Faktoren bestimmen die perioperative Mortalität: Primäre Graft (= Spenderorgan) Dysfunktion (PGD), non-CMV-Infektion, kardiovaskuläres Versagen und akute Abstoßung. PGD gilt als das wichtigste postoperative Problem. Diese tritt in der Regel innert der 24-72 h postoperativ auf und ist klinisch vergleichbar mit einem akuten respiratory distress syndrom (ARDS).

Um die Funktion des Spenderorganes zu erhalten ist postoperativ eine konsequente immunsuppressive Therapie erforderlich. In der Regel erfolgt eine Dreifachtherapie (unter Spiegelkontrolle) mit einem Calcineurinantagonisten (Tacrolimus oder Cyclosporin), einem antiproliferativen Medikament (Mycophenolate oder Azathioprim) und Steroiden.

\section{Postoperative Phase}

Langfristige Komplikationen nach der Transplantation bestehen in der akuten Abstoßung (AR; $35 \%$ im 1. postoperativen Jahr): Die Symptome sind unspezifisch (Dyspnoe, Fieber, Pleuraschmerz, FEV1 oder $\mathrm{O}_{2}$-Abfälle, CT-Veränderungen). Diagnostischer Goldstandard sind Lungenbiopsien. Hauptproblem bleibt die chronische Abstoßung, insbesondere die Bronchiolitis obliterans (BO). Klinisch imponiert diese durch fortschreitende Atemnot und eine irreversible Obstruktion in der Spirometrie. Risikofaktoren für BO sind rezidivierende AR, anti-HLA-Antikörper, Besiedlung mit Bakterien oder Pilzen, Atemwegsviren (bei RSV Ribaverin erforderlich), CMV-Pneumonitis und gastroösophagealer Reflux (GERD). Hauptursache der Morbidität und Mortalität nach der Trans- 
plantation sind Infektionen unter Immunsuppression. Am häufigsten sind pulmonale Infektionen durch Bakterien, gefolgt von CMV, Pilzen und Mykobakterien. Für CF-Patienten nach Lungentransplantation ist das Risiko für Malignome (Gastrointestinaltrakt, Haut) und lymphoproliferative Erkrankungen auf das 6-Fache erhöht.

\section{$4 \quad$ Exokrine Pankreasinsuffizienz}

Jobst Henker

\section{Klinische Symptome}

Die exokrine Pankreasinsuffizienz bei CF zeigt bereits kurz nach der Geburt die typischen Symptome von massigen, fettglänzenden, übelriechenden Stühlen als Folge der Maldigestion. Bei Nichterkennen der Gedeihstörung kann diese bis zur Atrophie führen. Während bei einer leichten exokrinen Pankreasinsuffizienz keine bis geringe Beschwerden (Bauchschmerzen, Meteorismus) bestehen, sind die Folgen einer schweren Pankresinsuffizienz gravierend. Durch die Maldigestion kommt es zu einem Mangel an Makro- und Mikronährstoffen mit entsprechenden Folgen. Bei schlechter Compliance oder schlechter Einstellung können Zustände von Vitaminmangel auftreten. Hier kann es zur Nachtblindheit infolge des Vitamin-A-Mangels und zu Augenmotilitätsstörungen und Gangstörungen aufgrund des Vitamin-E-Mangels kommen. Dabei handelt es sich um eine neuroaxonale Störung, die irreversibel ist im Gegensatz zur Nachtblindheit.

\section{Diagnose}

Das Vorhandensein von fettglänzenden, übelriechenden Stühlen bei gleichzeitig pathologischem Schweißtest lässt kaum einen Zweifel an der exokrinen Pankreasinsuffizienz. Die bildgebende Diagnostik, insbesondere die Ultraschalluntersuchung, lässt den Untersucher in den ersten Lebensjahren im Stich. Manchmal kann ein etwas echodichtes Pankreas beobachtet werden. Einige CF-Patienten zeigen sonografisch - zum Teil auch schon pränatal - einen echoreichen Schichtungstyp der Darmschlingen durch eine Verdickung der Submukosa.

Nach wie vor ist die quantitative Bestimmung der Gesamtfettausscheidung im Stuhl durch eine Stuhlsammlung über 3-5 Tage die beste Methode zur Diagnose einer exokrinen Pankreasinsuffizienz, auch zur Überprüfung der Effektivität der Pankreasenzymtherapie. Wenn die Stuhlfettausscheidung bei einer adäquaten Einfuhr mehr als $7 \mathrm{~g}$ Fett/Tag jenseits des Säuglingsalters übersteigt, liegt eine dekompensierte bzw. behandlungsbedürftige Pankreasinsuffizienz vor. Die Fettabsorption liegt bei Gesunden bie über $93 \%$ der aufgenommenen Menge. Patienten mit CF haben eine Fettausscheidung, die mehr als $10 \%$ der aufgenommen Menge beträgt. Aus der
Fettaufnahme mit der Nahrung und der Stuhlfettausscheidung lässt sich der Fettresorptionskoeffizient berechnen nach der Formel:

$$
\begin{aligned}
& \text { Fettresorptionskoeffizient } \\
& =\frac{\text { Fettaufnahem in } g-\text { Fettausscheidung in } g}{\text { Fettaufnahme in } g} \\
& \times 100
\end{aligned}
$$

Andere Pankreasfunktionstests wie die Bestimmung der fäkalen Elastase, der fäkalen Chymotrypsinaktivität, der Pankreolauryltest, ${ }^{13} \mathrm{C}$-Atemtest unter Verwendung verschiedener Tracer (1,3-Distearyl-2- ${ }^{13} \mathrm{C}-$ Octanoyl-Glycerin, Cholesteryl- ${ }^{13} \mathrm{C}$-Octanoat, ${ }^{13} \mathrm{C}$-Tripalmitin, ${ }^{13} \mathrm{C}$-Hiolein, ${ }^{13} \mathrm{C}$-Trioctanoin, ${ }^{13} \mathrm{C}$-Triolein und ${ }^{13} \mathrm{C}$-Maisstärke) haben einen guten Aussagewert für die Feststellung einer exokrinen Pankreasinsuffizienz, erlauben aber nur bedingt eine quantitative Beurteilung der Pankreasinsuffizienz.

\section{Therapie}

Liegt eine schwere Pankreasinsuffizienz vor, so ist eine Ersatztherapie mit Enzympräparaten indiziert. Die Enzympräparate stammen fast ausschließlich aus Schweinepankreas. Das in Pulverform vorliegende Pankreatin wird entsprechend der Pharmacopoeia Europea (Ph. Eur.) standardisiert. Die höchste Effektivität besitzen säuregeschützte, mikrosphärische, darmlösliche Präparate (Mikrotabletten oder -pellets). Die Mikrotabletten oder -pellets werden im Magen aus der meist aus Gelatine bestehenden Kapsel freigegeben, vermischen sich mit dem Speisebrei und sollten zeitgleich mit diesem den Magen verlassen. Voraussetzung dafür ist, dass sie nur 1-2 mm, besser unter 1,4 mm klein sind. Erst oberhalb eines pH-Werts von 5,5 - also erst im Duodenum - löst sich der Säureschutz der Mikrotabletten oder -pellets. Bei eingeschränkter pankreatogener Bikarbonatsekretion ist diese Voraussetzung nicht immer gegeben. Dann sollte zeitlich begrenzt ein Magensäureblocker eingesetzt werden. Diese Probleme können bei der Verwendung eines Präparates mit der Synthese von Lipase (aus Rhizopus oryzae), Protease (aus Aspergillus oryzae) und Amylase (aus Aspergillus oryzae) aus Schimmelpilzen weitestgehend vermieden werden (z. B. Nor$\left.\operatorname{tase}^{\mathbb{B}}\right)$. So hat die Rizolipase ein pH-Wirkspektrum von 3,5-7 und ist damit säurestabil.

Die Dosierung von Pankreasenzympräparaten sollte sich nach dem Fettgehalt der Nahrung richten. Durch Ernährungsschulungen lernen Patienten und/oder Eltern, den Fettanteil von Mahlzeiten einzuschätzen. Außerdem sollten sie lernen, mit Nährwerttabellen zu arbeiten. Als Richtwerte für die Dosierung der Enzympräparate gelten 1000-2500 (-5000) Lipaseeinheiten für $1 \mathrm{~g}$ Nahrungsfett bzw. 8000-10.000 (max. 15.000) Lipaseeinheiten/kg KG und Tag. Das Enzympräparat muss zur Mahlzeit eingenommen 
werden. Eine Ernährungsschulung ist mindestens 1-mal pro Jahr zu empfehlen.

Unter einer Enzymsubstitution kann die Ernährung energie- und fettreich sein, sodass der Fettanteil bis zu $40 \%$ der Gesamtenergie ausmachen kann. Der Energiegehalt kann bis zu $130 \%$ der für Alter und Geschlecht empfohlenen Menge betragen.

Zeigt die Ernährung auch nach Steigerung der Enzymdosis nicht den gewünschten Erfolg (unter anderem Gewichtsabnahme oder ungenügende Gewichtszunahme, anhaltend pathologische Stuhlentleerungen) sind ein 4-Tage-Ernährungsprotokoll zur Berechnung der Kalorienaufnahme sowie der Anteile von Fetten, Kohlenhydraten und Eiweißen zu erstellen und die Enzymtherapie sowie die PatientenCompliance (Bestimmung der fäkalen Chymotrypsinkonzentration) zu überprüfen. Ehe die Enzymtherapie deutlich erhöht wird, sollte eine 72-Stunden-Fettbilanz durchgeführt und danach entschieden werden, ob ein Teil der Fette als MCT-Fette verabreicht wird. MCT sind Triglyzeride mit Fettsäuren mittlerer Kettenlänge (,medium chain triglycerides“, 6-10 C-Atome). MCT werden unabhängig von Gallensäuren und Pankreaslipase im Darm resorbiert und ohne Bindung an Chylomikronen zur Leber transportiert.

Auch wenn die Gefahr einer fibrosierenden Kolonopathie durch extrem hohe Enzymdosen (>50.000 Lipaseeinheiten/ $\mathrm{kg} \mathrm{KG/Tag)} \mathrm{gering} \mathrm{ist,} \mathrm{sollten} \mathrm{diese} \mathrm{vermieden} \mathrm{werden.}$

Bei der fibrosierenden Kolonopathie handelt es sich um eine nichtentzündliche Kolonobstruktion, die mit beträchtlicher intramuraler Fibrose des Kolons einhergeht. Gewöhnlich sind das Colon ascendens und transversum betroffen. Die Patienten klagen über Symptome der Kolonobstruktion. Einige von ihnen mussten chirurgisch behandelt werden.

Etwa $20 \%$ der CF-Patienten haben eine exokrine Pankreassuffizienz mit Neigung zu rezidivierenden akuten Pankreatitiden.

\section{$5 \quad$ Pankreatogener Diabetes}

\section{Jobst Henker}

Bei einer schweren chronischen Erkrankung des exokrinen Pankreas, wie bei der Mukoviszidose, kann es zusätzlich zu einer endokrinen Pankreasinsuffizienz kommen, bei der der sog. pankreatogene Diabetes im Vordergrund steht. Je nach Alter sind $12-30 \%$ der CF-Patienten betroffen. Zur frühzeitigen Erfassung einer diabetischen Stoffwechsellage wird deshalb ab dem 10. Lebensjahr 1-mal pro Jahr ein oraler Glukosetoleranztest (oGTT) empfohlen. Der pankreatogene Diabetes kann mit einer Durchfallsymptomatik (diabetische Diarrhö) einhergehen, die nicht mit der Folge einer Maldigestion verwechselt werden sollte.

\section{$6 \quad$ Hepatobiliäre Komplikationen}

Jobst Henker

Durch die hohe Expression des CFTR in den Gallenwegen ist bei Fehlfunktion desselben das hepatobiliäre System in mannigfacher Weise bei CF betroffen.

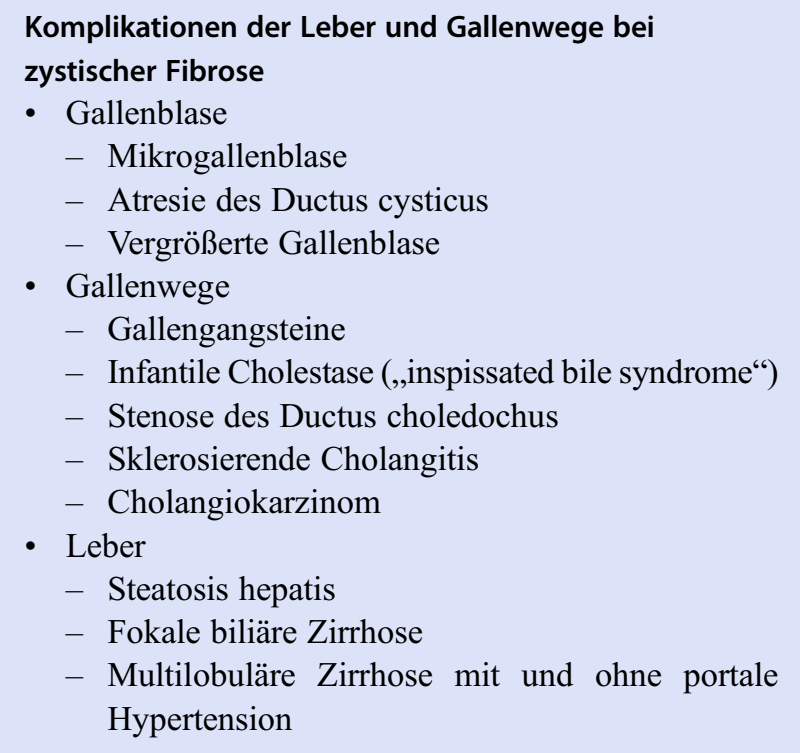

Hierbei kann die Gallenblase betroffen sein mit dem Auftreten einer Mikrogallenblase und Atresie des Ductus cysticus, einer erweiterten Gallenblase und Gallensteinen. Daneben können auch die großen Gallengänge betroffen sein, wie bei einer sklerosierenden Cholangitis. Die Leber selbst ist betroffen in Form einer fokalen oder multilobulären Zirrhose. Die fokale biliäre Zirrhose findet sich bereits bei $10-15 \%$ der CF-Kinder jünger als $1 \mathrm{Jahr}$, bei $20-50 \%$ aller CF-Patienten in der Kindheit und bei bis zu $72 \%$ der Erwachsenen mit CF. Die multilobuläre Zirrhose steigt von unter $1 \%$ bei Säuglingen und Kleinkindern auf $24 \%$ bei Erwachsenen mit $\mathrm{CF}$ an. Es ist immer wieder darüber spekuliert worden, ob die Schwere der Lungenmanifestation mit der Lebermanifestation korreliert. Dies ist aber nach den heutigen Kenntnissen nicht der Fall. Eine besondere Manifestation der Leberkrankheit bei CF stellt die seltene, aber länger verlaufende neonatale Cholestase der Neugeborenen dar. In einigen Fällen verlief die Symptomatik entsprechend der einer extrahepatischen Gallengangsatresie mit acholischen Stühlen. Nur ganz wenige wiesen eine extrahepatische Gallengangsatresie auf, die meisten jedoch nicht. Aus diesem Grund muss bei jedem Kind mit Verdacht auf extrahepatische Gallengangsatresie eine CF mittels Schweißtest oder molekulargenetischer Untersuchung ausgeschlossen werden. 


\section{Diagnose}

Die Diagnose der Hepatopathie bei CF ist schwierig. Die Ultraschalluntersuchung zusammen mit der Bestimmung der Leberfunktion in Blutuntersuchungen führt in der Regel weiter. Beim Ultraschall kann eine vermehrte Echogenität der Leber gefunden werden. Einfacher ist die Diagnose von Gallenblasen- oder Gallenganganomalien. Gallensteine, Gallengangsteine werden in der Regel sicher entdeckt. Schwierig bleibt die Diagnose einer extrahepatischen Gallengangsatresie. Eine Mikrogallenblase, die sich in ihrer Größe nicht ändert, unabhängig davon, ob der Patient nüchtern ist oder nicht, gibt einen gewissen Hinweis. Auch die Gallengangsszintigrafie mit HIDA (,hepatic iminodiacetic acid“) lässt den Untersucher im Einzelfall im Stich. Ist der Stuhl acholisch, findet sich auch eine pathologische Exkretion von HIDA in der Szintigrafie. Vor einer geplanten Laparotomie sollte ein Schweißtest, eine molekulargenetische Untersuchung oder gegebenenfalls eine Leberbiopsie zum Ausschluss anderer Erkrankungen durchgeführt werden.

Das Auftreten einer portalen Hypertension mit Ösophagusvarizen ist ein sicherer Hinweis auf die Entwicklung einer multilobulären biliären Zirrhose. Die Bestimmung der Standardleberwerte im Serum (Serum-Glutamat-Oxalacetat-Transaminase [SGOT], Serum-Glutamat-Pyruvat-Transaminase [SGPT], $\gamma$-Glutamyl-Transferase [ $\gamma$-GT], Gallensäuren) sowie Cholinesterase (CHE), Quick und Ammoniak als Parameter für die Entgiftungsfunktion gibt im Langzeitverlauf einen Hinweis auf die Leberfunktionsstörung. Eine Leberpunktion ist unzuverlässig, da sie meist nicht repräsentativ für das ganze Lebergewebe ist. Sie kann sogar bei multilobulärer Zirrhose als normal befundet sein.

\section{Therapie}

Die Behandlung der Leberfunktionsstörung bei CF ist schwierig. Neben der allgemeinen Therapie mit ausreichender Ernährung, Supplementierung von wasser- und fettlöslichen Vitaminen und der diuretischen Therapie bei Aszites hat sich die Gabe von Ursodesoxycholsäure etabliert. In einer Dosis von 15-20 mg/kg KG/Tag in 2-3 Einzeldosen gegeben hat diese Therapie in einigen Studien eine Verbesserung der Leberfunktion gezeigt. Eine kürzlich durchgeführte Cochrane-Analyse hat allerdings gezeigt, dass die Routinegabe von Ursodesoxycholsäure bei CF mit Leberbeteiligung noch nicht gerechtfertigt ist.

Die Ösophagusvarizen werden ebenso behandelt wie die von Patienten ohne CF. Die Sklerosierung der Varizen bzw. ihre Gummibandligatur sind die Methode der Wahl. In seltenen Fällen ist eine portokavale Shuntoperation notwendig, in der Regel ein peripherer splenorenaler Warren-Shunt. Die Entscheidung hierzu muss im Gesamtbild der Schwere der Krankheit getroffen werden. Sie wird durch die Schwere des Lungenbefalls beeinflusst. Im Einzelfall kann die Shuntoperation die Zeit bis zu einer Lebertransplantation jahrelang überbrücken. Mit diesem Vorgehen kann der Patient stabilisiert werden bis zu einer Transplantation, auch bis zu einer evtl. kombinierten Lungen-Leber-Transplantation. Aber auch eine singuläre Lebertransplantation bzw. eine singuläre Lungentransplantation bei Hepatopathie ist möglich. Die Überlebenszeit der transplantierten Patienten, unabhängig davon, ob eine isolierte Lebertransplantation oder Kombination mit Lungen- und Lebertransplantation bzw. Herz-, Lungen- und Lebertransplantation durchgeführt wurde, beträgt derzeit $85 \%$ nach 1 Jahr und $65 \%$ nach 5 Jahren.

\section{Intestinale Manifestationen}

Jobst Henker

Die intestinalen Manifestation der CF sind mannigfach und in der folgenden Übersicht zusammengefasst.

Intestinale Manifestationen der zystischen Fibrose

- Ösophagus

- Gastroösophagealer Reflux

- Ösophagitis

- Ösophagusstriktur

- Ösophagusvarizen

- Magen und Duodenum

- Peptischer Ulkus

- Dünndarm

- Mekoniumileus des Neugeborenen

- Dünndarmatresie bei Mekoniumperitonitis

- Distales intestinales Obstruktionssyndrom (DIOS)

- Invagination

- Morbus Crohn

- Zöliakie

- Appendix

- Akute Appendizitis

- Abszendierende Apendizitis

- Mukozele der Appendix

- Invagination der Appendix

- Kolon

- Obstipation, sekundäres Megakolon

- Pneumatosis intestinalis

- Fibrosierende Kolonopathie

- Antibiotika-assoziierte Kolitis (durch Clostridium difficile)

- Malignome (Adenokarzinome)

- Rektum

- Rektumprolaps

\section{1 Ösophagus und Magen}

Patienten mit CF leiden häufig unter einem gastroösophagealen Reflux (GÖR). Der GÖR wird mit einer Häufigkeit von 
$25 \%$ bei $\mathrm{CF}$ angegeben. Die Hälfte der Patienten mit GÖR entwickelt eine Ösophagitis. Der Reflux ist das Resultat der schweren Lungenerkrankung und ihrer Therapie mit Medikamenten, die den unteren Ösophagussphinkter relaxieren, des schweren Hustenreizes mit Kontraktion der Bauchmuskeln und des Zwerchfells sowie der Physiotherapie. Die Patienten mit GÖR klagen über Schmerzen hinter dem Brustbein, Sodbrennen, Dysphagie und Regurgitation. Die Diagnostik entspricht der bei GÖR ohne CF: Durchführung einer Ösophagogastroduodenoskopie zur Diagnose einer Ösophagitis, einer Striktur oder einer Hiatushernie. Die Therapie beinhaltet die Gabe von Protonenpumpenhemmern für durchaus längere Zeit. Eine Fundoplikatio ist nur äußerst selten indiziert. Magen- und Duodenalulzera werden nur sehr selten gefunden. Auch ist eine Helicobacter-pylori-Gastritis bei Patienten mit CF selten.

\subsection{Dünndarm}

Für die zwei wesentlichen Komplikationen der CF im Dünndarm, dem Mekoniumileus (MI) und dem distalen intestinalen Obstruktionssyndrom (DIOS) besteht ähnlich wie bei der Pankreasinsuffizienz eine gewisse Genotyp-Phänotyp-Korrelation. Fast ausschließlich bei Patienten mit schwerwiegenden Mutationen (wie z. B. bei Delta-F508/delta-F508-Homozygotie) und gleichzeitiger Pankreasinsuffizienz treten ein MI oder DIOS auf. Bei Patienten mit suffizienter Pankreasfunktion treten diese Komplikationen nicht auf. Der Zusammenhang ist wie bei der exokrinen Pankreasinsuffizienz in der mangelnden Funktion des CFTR zu suchen, der, sofern es den Dünndarm angeht, vermindert $\mathrm{Cl}^{-}$in das Lumen sezerniert. Dadurch kommt es zu Präzipitationen von Phospholipiden, vor allem Lecithin. Durch die eingenommenen Pankreasersatzpräparate wird das akkumulierte Lecithin $\mathrm{zu}$ Lysolecithin umgewandelt. Da aber die gleichen Extrakte keine Lysolecithinase enthalten, kommt es zu einer Anhäufung von Lysolecithin, welches durch seine hydrophobe Natur in der Lage ist, Epithelzellen zu zerstören. Eine gleichzeitig vorhandene abnorme Schleimproduktion, die exokrine Pankreasinsuffizienz, der verminderte Chloridtransport und eine herabgesetzte intestinale Motilität tragen zum Auftreten des Mekoniumileus und des DIOS bei.

\section{Mekoniumileus}

10-20\% aller Neugeborenen mit CF weisen einen Mekoniumileus auf, der durch eine Obstruktion des distalen Dünndarms infolge zähen Mekoniums im terminalen Ileums charakterisiert ist. Der Mekoniumileus tritt bereits in utero auf. In $10 \%$ aller Fälle mit Mekoniumileus kommt es schon während der Schwangerschaft zur Perforationen des Dünndarms und zum Auftreten einer sterilen Mekoniumperitonitis, die radiologisch durch die charakteristischen Verkalkungen im

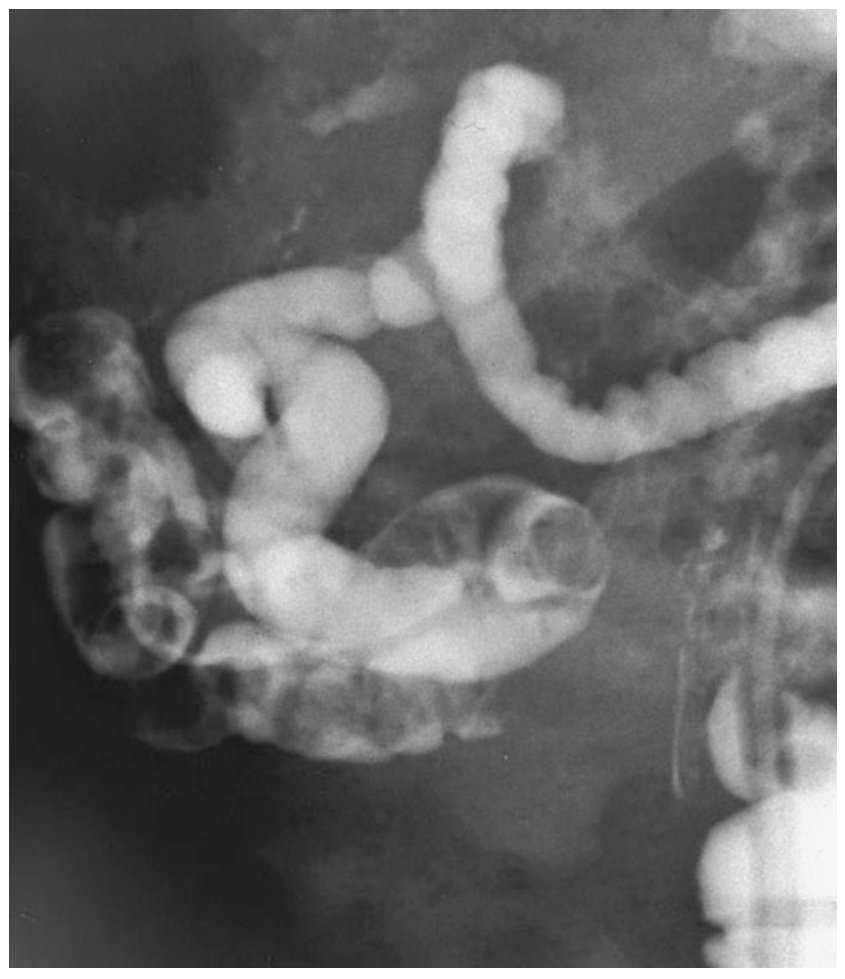

Abb. 6 Mekoniumileus mit Darstellung von Stuhlmassen im terminalen Ileum eines Neugeborenen. Außerdem sind kalkspritzerartige Flecken im Abdomen als Folge der stattgefundenen Mekoniumperitonitis in utero sichtbar. (Mit freundl. Genehmigung von Dr. D. Emons, Radiologie des Zentrums für Kinderheilkunde Bonn)

Abdomen erkannt werden kann. Klinisch präsentieren sich die Neugeborenen durch das Fehlen von Mekoniumabgang in den ersten 48 Stunden sowie die zunehmenden Zeichen des mechanischen Ileus im unteren Gastrointestinaltrakt. Eine Abdomenleeraufnahme zeigt die typischen Zeichen des Ileus (Abb. 6). Der Mekoniumileus ist praktisch pathognomonisch für eine CF. Eine entsprechende Diagnostik mit Schweißtest und Molekulargenetik muss immer erfolgen. Therapie ist in der Regel die chirurgische Intervention mit Beseitigung des Ileus durch mechanisches Entleeren des Mekoniums. Manchmal muss eine vorübergehende Ileostomie angelegt werden.

\section{Distales intestinales Obstruktionssyndrom (DIOS)}

Nach der Neugeborenenperiode tritt bei älteren Patienten mit $\mathrm{CF}$ eine dem Mekoniumileus sehr ähnliche Krankheit auf mit distaler Obstruktion im terminalen Ileum und proximalen Kolon durch eingedickten Darminhalt. Früher wurde diese Symptomatik als Mekoniumileusäquivalent bezeichnet. Heute bezeichnen wir diese Symptomatik international als DIOS. Es tritt mit einer Häufigkeit von $5-7,5 \%$ in 1000 Patientenjahren in der Altersklasse der 15- bis 20-Jährigen auf und bis zu $35 \%$ in 1000 Patientenjahren in der Altersgruppe der 20- bis 25-Jährigen. Die Ätiologie ist unklar. Das 
DIOS tritt in der Regel nur bei Patienten mit exokriner Pankreasinsuffizienz auf.

\section{Klinische Symptome und Diagnose}

Die Symptome sind starke Bauchschmerzen in Form von Koliken, Erbrechen, selten auch Erbrechen von Galle und Darminhalt, ein geblähtes Abdomen, das bei der Palpation eine peritoneale Abwehrspannung aufweisen kann. Im rechten unteren Quadranten tastet man verschiebliche Massen. Die Palpation ist schmerzhaft. Differenzialdiagnostisch ist an eine Appendizitis zu denken, die in einzelnen Fällen gleichzeitig zum DIOS vorkommen kann. Ebenso kann eine gleichzeitige Invagination vorliegen. Die Diagnose kann in den meisten Fällen durch die Ultraschalluntersuchung gestellt werden. Hierbei ist die manchmal gleichzeitig vorhandene Invagination durch die typische Kokarde gut sichtbar $\mathrm{zu}$ machen. Eine Abdomenleeraufnahme weist ebenfalls auf die distale Obstruktion hin (Abb. 7). Das DIOS ist häufig bei CF-Patienten nach einer Lungentransplantation.

\section{Therapie}

Die Therapie des DIOS ist, soweit möglich, konservativ mit der oralen Gabe von großen Mengen von isoosmotischen

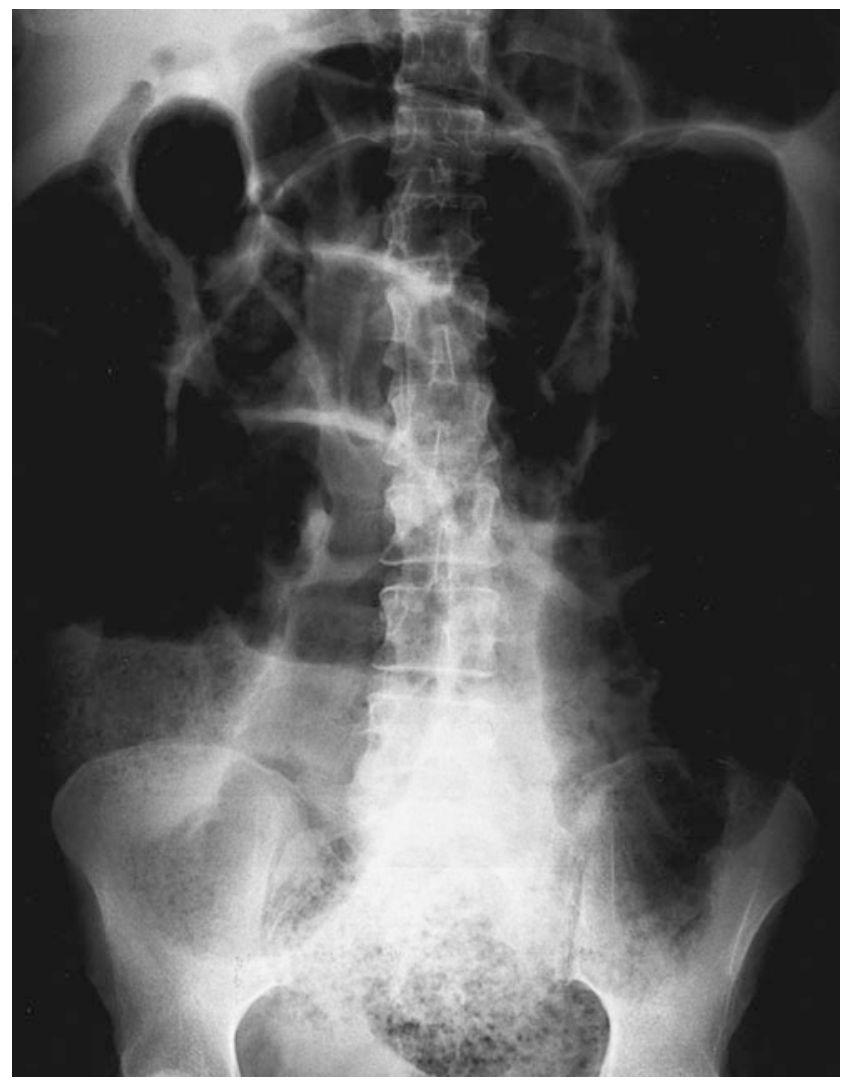

Abb. 7 Abdomenleeraufnahme im Liegen bei einem erwachsenen Patienten mit CF und DIOS. Neben den Zeichen eines distalen Ileus mit stark geblähten Dünndarmschlingen sind die Stuhlimpaktionen im distalen Ileus und die fehlende Luft im Raum sichtbar
Polyethylenglykollösungen (= Macrogol). Voraussetzung ist dabei allerdings der Ausschluss eines manifesten mechanischen Ileus oder einer Invagination. Hier kann eine vorsichtige rektale Spülung mit der gleichen Lösung versucht werden. Kommt es durch die Gabe von Polyethylenglykollösungen nicht zur Entleerung der Impaktionen, ist eine chirurgische Intervention anzustreben. Da sich das DIOS bei Patienten mit CF immer wiederholen kann, ist dies für die betroffenen Patienten eine schwere Beeinträchtigung ihrer Lebensqualität. Die kontinuierliche Einnahme von Polyethylenglykollösungen zu Hause vermindert die Zahl der DIOS und damit die stationäre Behandlung dieses Leidens im Krankenhaus. Bei rezidivierendem DIOS kann sogar an eine Kolon-PEG (perkutane endoskopische Gastrostomie) gedacht werden.

\subsection{Appendix}

Der Befall der Appendix bei CF kommt in verschiedenen Krankheitsentitäten vor. Sowohl eine akute Appendizitis wurde hierbei beschrieben als auch eine abszedierende Appendizitis, die purulente Mukozele der Appendix und die Invagination der Appendix mit rektaler Blutung. Die typischen Appendizitiszeichen im rechten Unterbauch, eine Abwehrspannung als Zeichen der lokalen Peritonitis sollten an diese Möglichkeiten denken lassen. Diagnostisch kann eine Ultraschalluntersuchung weiterhelfen. Die chirurgische Intervention ist hier die Therapie der Wahl.

\subsection{Clostridium-difficile-Kolitis}

Bei Adoleszenten oder Erwachsenen mit CF wird das Auftreten von schweren Kolitiden beobachtet, die mit schweren wässrigen Durchfällen, Bauchschmerzen und schlechtem Allgemeinzustand einhergehen. Das vermehrte Auftreten von Durchfällen wird anfänglich falsch als Versagen der Pankreasersatztherapie gedeutet. Erst die Darstellung des Kolons mit Ultraschall oder mittels CT des Abdomens zeigt dann ein monströs verdicktes Kolon im Sinne einer Pankolitis (Abb. 8). In der Regel kann dann Clostridium difficile im Stuhl nachgewiesen werden. Diese Form der Kolitis unterscheidet sich grundsätzlich von der pseudomembranösen Kolitis, die ebenfalls durch C. difficile hervorgerufen wird. Die Pankolitis verläuft sehr schwer, in einigen Fällen mit tödlichem Ausgang. Sie kann als Antibiotika-assoziierte Kolitis interpretiert werden. Die Frage der Herkunft der C.-difficile-Bakterien ist unklar. Neben der nosokomialen Übertragung muss auch die asymptomatische Dauerausscheidung von CF-Patienten in Betracht gezogen werden. Die Therapie besteht in der intravenösen Gabe von Vancomycin und Metronidazol über längere Zeit (3-4 Wochen). Morpho- 


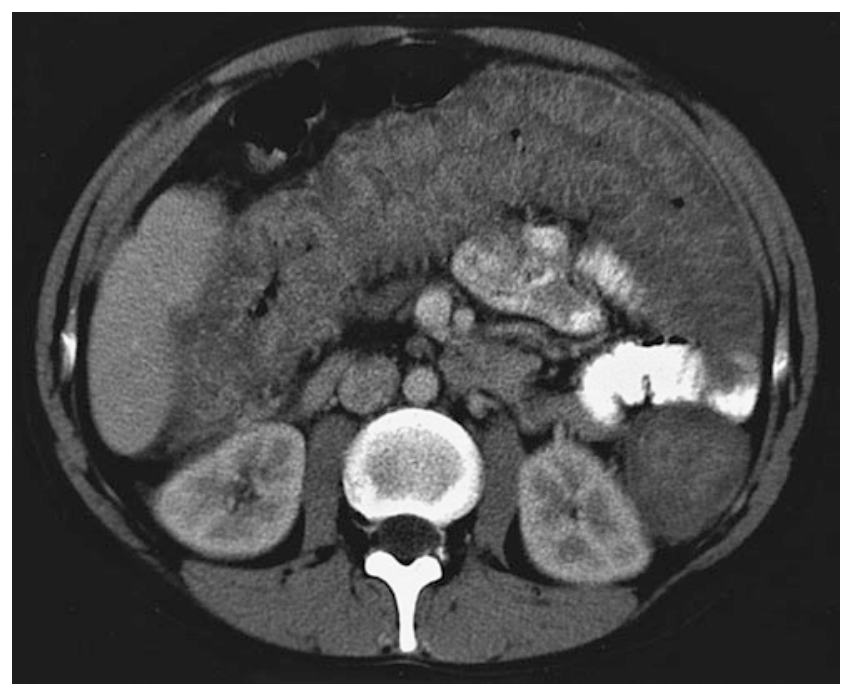

Abb. 8 Die Computertomografie mit Kontrastmittel des Abdomens zeigt ein monströs verdicktes Kolon bei einem erwachsenen Patienten mit CF und Clostridium difficile. (Mit freundl. Genehmigung von Prof. Schild, Radiologische Klinik)

logisch bildet sich die schwere Kolitis nur langsam zurück. Verlaufskontrollen können mittels Ultraschall erfolgen. Die monströs verdickte Kolonwand bzw. ihre Rückbildung sind hierbei einfach zu beurteilen

\subsection{Rektumprolaps}

Der Rektumprolaps kommt typischerweise bei CF-Kindern unter 5 Jahren vor und tritt häufiger bei Pankreasinsuffizienz auf. Er wird in der Regel vor der Diagnosestellung beobachtet. Die Ursache ist nicht vollkommen geklärt, sie wird dem starken Drücken bei der Defäkation von massigen Stühlen bzw. der Obstipation bei hohen Dosen von Pankreasersatzpräparaten zugeschrieben und auch dem ständigen Hustenreiz und damit verbundener Bauchpresse. Alle Kinder mit einem isolierten Rektumprolaps benötigen einen Schweißtest. Eine spezifische Therapie existiert nicht, in der Regel ist der Rektumprolaps selbstlimitierend durch die Behandlung der CF entweder durch die Substitution der Pankreasenzyme oder durch die Therapie der Obstipation mit Laxanzien (Laktulose).

\subsection{Seltene andere Manifestationen im Gastrointestinaltrakt}

Bei erwachsenen Patienten mit CF wurden in den letzten Jahren Malignome im Gastrointestinaltrakt beobachtet. Hierbei wurden in der Mehrzahl der Fälle Adenokarzinome im Dünn- und Dickdarm diagnostiziert, aber auch Ösophagus-, Magen- und Pankreaskarzinome. Daher ist bei erwachsenen
Patienten mit ungewöhnlichen gastrointestinalen Symptomen, wie Anämie, rektalen Blutungen oder nicht DIOS-abhängigen Obstruktionen, an die Möglichkeit einer malignen Entartung zu denken.

Infektionen mit Giardia lamblia wurden bei Patienten mit $\mathrm{CF}$ häufiger beobachtet als in der gesunden Normalbevölkerung. Bei $28 \%$ der Kinder mit CF und $44 \%$ der Erwachsenen konnten Giardia lamblia gefunden werden. Auch wurde der Morbus Crohn häufiger bei Patienten mit CF beobachtet als bei Gesunden. Die übliche Diagnostik mit oberer und unterer Endoskopie kann in diesen Fällen die Diagnose stellen. Insbesondere bei Symptomen wie Bauchschmerzen, Anämie, Hypoproteinämie und extraintestinalen Symptomen wie Arthritis sollte an das Vorliegen einer chronisch-entzündlichen Darmerkrankung gedacht werden. Die Abgrenzung zur fibrosierenden Kolonopathie erfolgt vor allem histologisch. Selten wird neben der CF eine Zöliakie beobachtet. Bei Patienten, die trotz guter Einstellung mit Pankreasersatzpräparaten und adäquater kalorischer Ernährung weiterhin Symptome einer Malabsorption aufweisen, ist die Bestimmung der Anti-Endomysium- oder Anti-Transglutaminase-Antikörper bei Ausschluss eines IgA-Mangels hilfreich, bevor durch die Dünndarmbiopsie die Diagnose gestellt wird.

\section{Weiterführende Literatur}

\section{Weiterführende Literatur zu Abschnitt 1 bis 3}

Aaron SD, Vandemheen KL, Freitag A, Pedder L, Cameron W, Lavoie A, Paterson N, Wilcox P, Rabin H, Tullis E, Morrison N, Ratjen F (2012) Treatment of Aspergillus fumigatus in patients with cystic fibrosis: a randomized, placebo-controlled pilot study. PLoS One 7(4):e36077

Bilton D, Canny G, Conway S, Dumcius S, Hjelte L, Proesmans M, Tümmler B, Vavrova V, De Boeck K (2011) Towards a definition for use in clinical trials. Report from the EuroCareCF Working Group on outcome parameters in clinical trials. J Cyst Fibros 10(Suppl 2): S79-S81

Brody AS, Klein JS, Molina PL, Quan J, Bean JA, Wilmott RW (2004) High-resolution computed tomography in young patients with cystic fibrosis: distribution of abnormalities and correlation with pulmonary function tests. J Pediatr 145(1):32-38

Cantin AM, Hartl D, Konstan MW, Chmiel JF (2015) Inflammation in cystic fibrosis lung disease: pathogenesis and therapy. J Cyst Fibros 14(4):419-430

Castellani C, Cuppens H, Macek M Jr, Cassiman JJ, Kerem E, Durie P, Tullis E, Assael BM, Bombieri C, Brown A, Casals T, Claustres M, Cutting GR, Dequeker E, Dodge J, Doull I, Farrell P, Ferec C, Girodon E, Johannesson M, Kerem B, Knowles M, Munck A, Pignatti PF, Radojkovic D, Rizzotti P, Schwarz M, Stuhrmann M, Tzetis M, Zielenski J, Elborn JS (2008) Consensus on the use and interpretation of cystic fibrosis mutation analysis in clinical practice. J Cyst Fibros 7(3):179-196

Chrispin AR, Norman AP (1974) The systematic evaluation of the chest radiograph in cystic fibrosis. Pediatr Radiol 2:101-105

Collaco JM, Vanscoy L, Bremer L, McDougal K, Blackman SM, Bowers A, Naughton K, Jennings J, Ellen J, Cutting GR (2008) Interactions between secondhand smoke and genes that affect cystic fibrosis lung disease. JAMA 299(4):417-424 
Cutting GR (2015) Cystic fibrosis genetics: from molecular understanding to clinical application. Nat Rev Genet 16(1):45-56

Cystic Fibrosis Foundation. CF Foundation Patient Registry annual data report 2011, CF Foundation 2012

Cystic Fibrosis Genotype-Phenotype Consortium (1993) Correlation between genotype and phenotype in patients with cystic fibrosis. The Cystic Fibrosis Genotype-Phenotype Consortium. N Engl J Med 329(18):1308-1313

Döring G, Hoiby N, Consensus Study Group (2004) Early intervention and prevention of lung disease in cystic fibrosis: a European consensus. J Cyst Fibros 3(2):67-91

Drumm ML, Konstan MW, Schluchter MD, Handler A, Pace R, Zou F, Zariwala M, Fargo D, Xu A, Dunn JM, Darrah RJ, Dorfman R, Sandford AJ, Corey M, Zielenski J, Durie P, Goddard K, Yankaskas JR, Wright FA, Knowles MR, Gene Modifier Study Group (2005) Genetic modifiers of lung disease in cystic fibrosis. N Engl J Med 353(14):1443-1453

ECFS Patient registry, Annual data report 2015

Ewijk BE van, van der Zalm MM, Wolfs TF, Fleer A, Kimpen JL, Wilbrink B, van der Ent CK. Prevalence and impact of respiratory viral infections in young children with cystic fibrosis: prospective cohort study. Pediatrics 2008; 122(6): 1171-1176

Floto RA, Olivier KN, Saiman L, Daley CL, Herrmann JL, Nick JA, Noone PG, Bilton D, Corris P, Gibson RL, Hempstead SE, Koetz K, Sabadosa KA, Sermet-Gaudelus I, Smyth AR, van Ingen J, Wallace RJ, Winthrop KL, Marshall BC, Haworth CS, US Cystic Fibrosis Foundation and European Cystic Fibrosis Society (2016) US Cystic Fibrosis Foundation and European Cystic Fibrosis Society consensus recommendations for the management of non-tuberculous mycobacteria in individuals with cystic fibrosis. Thorax 71(Suppl 1):i1-22

Gustafsson PM, De Jong PA, Tiddens HA, Lindblad A (2008) Multiplebreath inert gas washout and spirometry versus structural lung disease in cystic fibrosis. Thorax 63(2):129-134

Hector A, Kirn T, Ralhan A et al (2016) Microbial colonization and lung function in adolescents with cystic fibrosis. J Cyst Fibros 15(3):340-349

Kappler M, Nagel F, Feilcke M, Kröner C, Pawlita I, Naehrig S, Ripper J, Hengst M, von Both U, Forstner M, Hector A, Griese M (2016) Eradication of methicillin resistant Staphylococcus aureus detected for the first time in cystic fibrosis: a single center observational study. Pediatr Pulmonol 51(10):1010-1019

Kerem E, Corey M, Kerem BS, Rommens J, Markiewicz D, Levison H, Tsui LC, Durie P (1990) The relation between genotype and phenotype in cystic fibrosis - analysis of the most common mutation (delta F508). N Engl J Med 323(22):1517-1522

Konigsbruggen-Rietschel van et al (2017) Mukoviszidose: Erkrankung auf dem Weg zur personalisierten Therapie. Monatsschr Kinderheilkd 165(8):681-687

Lahiri T, Hempstead SE, Brady C, Cannon CL, Clark K, Condren ME, Guill MF, Guillerman RP, Leone CG, Maguiness K, Monchil L, Powers SW, Rosenfeld M, Schwarzenberg SJ, Tompkins CL, Zemanick ET, Davis SD (2016) Clinical practice guidelines from the Cystic Fibrosis Foundation for preschoolers with cystic fibrosis. Pediatrics 137(4). pii: e20151784

Lubamba BA, Jones LC, O’Neal WK, Boucher RC, Ribeiro CM (2015) $\mathrm{X}$-box-binding protein 1 and innate immune responses of human cystic fibrosis alveolar macrophages. Am J Respir Crit Care Med 192(12):1449-1446

McKone EF, Goss CH, Aitken ML (2006) CFTR genotype as a predictor of prognosis in cystic fibrosis. Chest 130(5):1441-1447

Meyerholz DK, Stoltz DA, Namati E, Ramachandran S, Pezzulo AA, Smith AR et al (2010) Loss of cystic fibrosis transmembrane regulator function produces abnormalities in tracheal develpment in neonatal pigs and young children. Am J Respir Crit Care Med 182:1251-1261
Mogayzel PJ Jr, Naureckas ET, Robinson KA, Mueller G, Hadjiliadis D, Hoag JB, Lubsch L, Hazle L, Sabadosa K, Marshall B, Pulmonary Clinical Practice Guidelines Committee (2013) Cystic fibrosis pulmonary guidelines. Chronic medications for maintenance of lung health. Am J Respir Crit Care Med 187(7):680-689

Morgan WJ, Wagener JS, Pasta DJ et al (2017) Relationship of antibiotic treatment to recovery after acute FEV1 decline in children with cystic fibrosis. Ann Am Thorac Soc 14(6):937-942

Muhlebach MS, Beckett V, Popowitch E, Miller MB, Baines A, MayerHamblett N, Zemanick ET, Hoover WC, VanDalfsen JM, Campbell P, Goss CH, STAR-too study team (2017) Microbiological efficacy of early MRSA treatment in cystic fibrosis in a randomised controlled trial. Thorax 72(4):318-326

Müller FM, Bend J, Rietschel E. S3 - Leitlinie „Lungenerkrankung bei Mukoviszidose“, Modul 1: Diagnostik und Therapie nach dem ersten Nachweis von Pseudomonas aeruginosa. Stand 06/13

Naehrlich L, Stuhrmann-Spangenberg M, Barben J et al. S2-KonsensusLeitlinie „Diagnose der Mukoviszidose“ (AWMF 026-023). Stand $06 / 2013$

Nahrig S et al (2017) Dtsch Arztebl Int 114:564-574

Nährlich L, Burkhart M, Weise B. Deutsches MukoviszidoseregisterBerichtband 2016

National Institute of Health and Care Excellence (2017) Final, Cystic fibrosis diagnosis and management. NICE guideline NG 78

Paemka L, McCullagh BN, Abou Alaiwa MH, Stoltz DA, Dong Q, Randak CO, Gray RD, McCray PB Jr (2017) Monocyte derived macrophages from $\mathrm{CF}$ pigs exhibit increased inflammatory responses at birth. J Cyst Fibros 16(4):471-474

Rosenfeld M, Allen J, Arets BH, Aurora P et al (2013) An official American Thoracic Society workshop report: optimal lung function tests for monitoring cystic fibrosis, bronchopulmonary dysplasia, and recurrent wheezing in children less than 6 years of age. Ann Am Thorac Soc 10(2):S1-S11

Rowe SM, Daines C, Ringshausen FC, Kerem E, Wilson J, Tullis E, Nair N, Simard C, Han L, Ingenito EP, McKee C, Lekstrom-Himes J, Davies JC (2017) Tezacaftor-ivacaftor in residual-function heterozygotes with cystic fibrosis. N Engl J Med 377(21):2024-2035

Sagel SD, Gibson RL, Emerson J, McNamara S, Burns JL, Wagener JS, Ramsey BW, Inhaled Tobramycin in Young Children Study Group, Cystic Fibrosis Foundation Therapeutics Development Network (2009) Impact of Pseudomonas and Staphylococcus infection on inflammation and clinical status in young children with cystic fibrosis. J Pediatr 154(2): 183-188

Schrijver I, Pique L, Graham S, Pearl M, Cherry A, Kharrazi M (2016) The spectrum of CFTR variants in nonwhite cystic fibrosis patients: implications for molecular diagnostic testing. J Mol Diagn 18(1):39-50

Schwarz C, Düesberg U, Bend J, Schulte-Hubbert B, van Koningsbruggen-Rietschel S. S3-Leitlinie: Lungenerkrankung bei Mukoviszidose, Modul 2: Diagnostik und Therapie bei der chronischen Infektion mit Pseudomonas aeruginosa. Stand: 06/2017

Sens B, Stern M (2013) Qualitätssicherung Mukoviszidose 2012. Hippocampus Verlag, Bad Honnef

Sermet-Gaudelus I, Mayell SJ, Southern KW, European Cystic Finrosis Society (ECFS), Neonatal Screening Working Group (2010) Guidelines on the early management of infants diagnosed with cystic fibrosis following newborn screening. J Cyst Fibros 9(5):323-329

Sly PD, Brennan S, Gangell C, de Klerk N, Murray C, Mott L, Stick SM, Robinson PJ, Robertson CF, Ranganathan SC, Australian Respiratory Early Surveillance Team for Cystic Fibrosis (AREST-CF) (2009) Lung disease at diagnosis in infants with cystic fibrosis detected by newborn screening. Am J Respir Crit Care Med 180(2):146-152

Sommerburg O, Hammermann J, Lindner M et al (2015) Five years of experience with biochemical cystic fibrosis newborn screening based on IRT/PAP in Germany. Pediatr Pulmonol 50:655-664

Stevens DA, Moss RB, Kurup VP, Knutsen AP, Greenberger P, Judson MA, Denning DW, Crameri R, Brody AS, Light M, Skov M, 
Maish W, Mastella G, Participants in the Cystic Fibrosis Foundation Consensus Conference (2003) Allergic bronchopulmonary aspergillosis in cystic fibrosis - state of the art: Cystic Fibrosis Foundation Consensus Conference. Clin Infect Dis 37(Suppl 3):S225-S264

Tarique AA, Sly PD, Holt PG, Bosco A, Ware RS, Logan J, Bell SC, Wainwright CE, Fantino E (2017) CFTR-dependent defect in alternatively-activated macrophages in cystic fibrosis. J Cyst Fibros 16(4):475-482

Taylor-Cousar JL, Munck A, McKone EF, van der Ent CK, Moeller A, Simard C, Wang LT, Ingenito EP, McKee C, Lu Y, Lekstrom-Himes J, Elborn JS (2017) Tezacaftor-ivacaftor in patients with cystic fibrosis homozygous for Phe508del. N Engl J Med 377(21):2013-2023

Tümmler et al (2016) Therapie der Mukoviszidose mit CFTRModulatoren. Pneumologie

Verhaeghe C, Delbecque K, de Leval L, Oury C, Bours V (2007) Early inflammation in the airways of a cystic fibrosis foetus. J Cyst Fibros 6(4):304-308

Wainwright CE, Elborn JS, Ramsey BW, Marigowda G, Huang X, Cipolli M, Colombo C, Davies JC, De Boeck K, Flume PA, Konstan MW, McColley SA, McCoy K, McKone EF, Munck A, Ratjen F, Rowe SM, Waltz D, Boyle MP, TRAFFIC Study Group, TRANSPORT Study Group (2015) Lumacaftor-ivacaftor in patients with cystic fibrosis homozygous for Phe508del CFTR. N Engl J Med 373(3):220-231

Waters V, Ratjen F (2015) Pulmonary exacerbations in children with cystic fibrosis. Ann Am Thorac Soc 12(Suppl 2):S200-S206

World Health Organization. The molecular genetic epidemiology of cystic fibrosis. www.who.Int/genomics/publications/reports/en/index.html www.genet.sickkids.on.ca/cftr/apps

\section{Weiterführende Literatur zu Abschnitt 4 bis 7}

AWMF-Leitlinie (2013a) S3-Leitlinie „Lungenerkrankung bei Mukoviszidose“. Modul 1: Diagnostik und Therapie nach dem ersten
Nachweis von Pseudomonas aeruginosa. www.awmf.org. Zugegriffen am 27.08.2013

AWMF-Leitlinie (2013b) S2-Konsensus-Leitlinie „Diagnose der Mukoviszidose“ (AWMF 026-023) unter Federführung der Gesellschaft für Pädiatrische Pneumologie. www.awmf.org. Zugegriffen am 27.08.2013

Borowitz DS, Grand RJ, Durie PR, The Consensus Committee (1995) Use of pancreatic enzyme supplements for patients with cystic fibrosis in the context of fibrosing colonopathy. J Pediatr 127:681-684

Flume PA et al (2007) Cystic fibrosis pulmonary guidelines. Chronic medications for maintenance of lung health. Am J Respir Crit Care Med 176:957-969

Flume PA et al (2009) Cystic fibrosis pulmonary guidelines. Treatment of pulmonary exacerbations. Am J Respir Crit Care Med 180:802-808

Flume P et al (2010) Cystic fibrosis pulmonary guidelines. Hemoptysis and pneumothorax. Am J Respir Crit Care Med 182:298-306

Henker J (2017) Exokrine Pankreasinsuffizienz im Kindesalter. Ernährungs Umsch Sonerheft 52-58

Kerem E, Corey M, Kerem BS et al (1990) The relation between genotype and phenotype in cystic fibrosis - analysis of the most common mutations. N Engl J Med 323:1517-1522

Lentze MJ (2001) Gastrointestinale Manifestationen der CF. Monatsschr Kinderheilkd 149:239

Mogayzel PJ et al (2013) Cystic fibrosis pulmonary guidelines. Chronic medications for maintenance of lung health. Am J Respir Crit Care Med 187:680-689

O'Sullivan BP, Freedman SD (2009) Cystic fibrosis. Lancet 373:1891-1894

Ratjen FA (2009) Cystic fibrosis: pathogenesis and future treatment strategies. Respir Care 54(5):595-602

Riordan JR, Rommens JM, Kerem B et al (1989) Identification of the cystic fibrosis: cloning and characterization of complementary DNA. Science 245:1066-1072

Sinaasappel M, Stern M, Littlewood J et al (2002) Nutrition in patients with cystic fibrosis: a European consensus. J Cyst Fibros 1:51-75 